\title{
Towards a Design Model for Women's Empowerment in the Developing World
}

\author{
Geeta Shroff \\ CMU-CS-10-148 \\ November 2010 \\ School of Computer Science \\ Computer Science Department \\ Carnegie Mellon University \\ Pittsburgh, PA \\ Thesis Committee \\ Matthew Kam, Chair \\ Justine Cassell \\ Submitted in partial fulfillment of the requirements \\ for the Degree of Master of Science
}

\section{Copyright (C) 2010 Geeta Shroff}

This research was sponsored by a National Science Foundation (NSF) Graduate Research

Fellowship and Nokia Research. Any opinions, findings, conclusions or recommendations expressed in this material are those of the authors and do not necessarily represent the views of NSF, Nokia or Carnegie Mellon University. 
Keywords: Computers and society, Design for inclusion, Developing countries, Digital divide, Feminist HCI, Gender equality, Human-Computer Interaction (HCI), Human Computer Interaction for Development (HCI4D), Information and Communication Technologies and Development (ICTD), Women's empowerment 


\section{Abstract}

Pulitzer Prize-winning journalist Nicholas Kristof argues that "in this century the paramount moral challenge will be the struggle for gender equality around the world." We present a design model for promoting women's empowerment in the developing world that cuts across individual application areas and allows the HCI community to characterize the escape path for low-income women from the vicious cycle of poverty. We conducted research in which our field studies took place over 15 weeks in 3 phases, with a total of 47 staff members from various non-government organizations, as well as 35 socio-economically challenged women in rural and urban India. Our results show that the women supported by the NGOs appear to belong to five different stages of development. We refined our understanding of our population through co-design sessions with NGOs and women using 7 proof-of-concept prototypes. We also present the application designs and our lessons from these sessions. 


\section{Acknowledgements}

I am foremost grateful to my advisor, Matthew Kam, for having given me the opportunity, support, and continuous guidance in pursuing this project of my dreams, for being patient with me through my health episodes, and from whom I yet have a lot to learn. I thank the MILLEE team and staff at Berkeley, CMU, and in India, in helping as and when needed for the logistics involved in this offshoot project. I would also like to thank my mentor at our partnering institution in India, Dr. Urvashi Sahni, for her support and guidance in making this possible, as well as the rest of the Study Hall Educational Foundation staff for their guidance and support. In particular, I thank Sangeeta Anand for her encouragement and inspiring field stories that kept me going during my field work in India. I would like to show my gratitude to all the undergraduate and local team members in India who have had a hand in making this project a reality - Kartikey Singh, who assisted me with all three phases of this project, as well as Aman Anand, Suryavir Sood, Dootika Vats, Pratik Chowdhury and Vaibhav Mandhyan. I am grateful to all the NGO staff and women that participated in this research, whose contagious passion for development has given me even more inspiration to see this project grow. I would also like to express my thanks to the lawyers and advisors in the IRB office for having guided me through the process of obtaining IRB approval for this project, and my advisor's administrative assistant, Jo Bodnar, for her guidance in obtaining financial and administrative approvals as and when needed for international transfers and field work. I thank Nokia for donating phones that we could use for application development and during co-design sessions with the participants. I am grateful to my academic department and NSF advisors, Deb Cavlovich and Suzie Laurich-McIntyre, for having been so understanding in giving me the time and platform to pursue this project at my own pace. I would also like to thank Linda Babcock and Jeria Quesenberry for their guidance during the beginning days of this project, and my second reader, Justine Cassel for her encouragement and time.

I am also grateful to my in-laws (Anjali Singh, Vinod Singh), sister-in-law (Dootika Vats), parents (Sadhana Shroff, Sharad Shroff), sister (Neeta Shroff), and other relatives and friends for their constant encouragement through the research and in giving me the strength to deal with the workload in spite of my regular pancreatitis episodes and hospitalizations. I would also like to thank my doctors for having worked out temporary solutions to my chronic health condition so that I could finish this thesis before heading to surgery. Last but not least, this would not have been possible without the support of my best friend and husband, Divyanshu Vats, for having balanced his own graduate work, my health, and our home, while still always having joined me through each of the ups and downs of this 9 month intensive roller coaster of a research project. I dedicate this thesis to him. 


\section{Contents}

1 Introduction ................................................................. 09

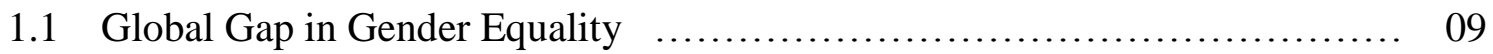

1.2 Women's Empowerment for Socio-economic Development ................. 09

1.3 Research Questions in Designing for Women's Empowerment ............. 10

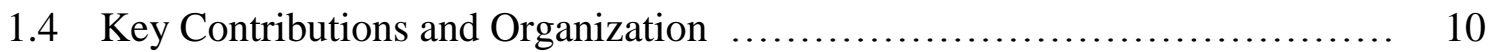

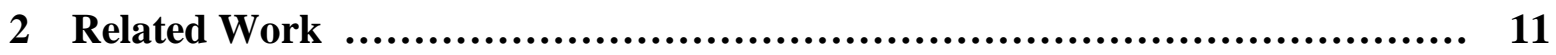

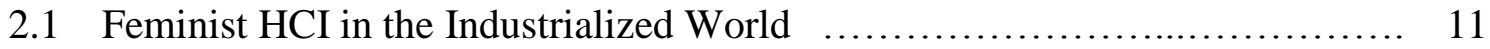

2.2 Feminist $\mathrm{HCI}$ in the Developing World ................................ 11

2.3 Design Models and Frameworks for Women's Empowerment .............. 12



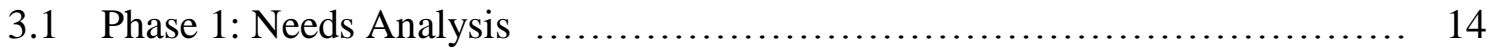

3.2 Phase 2: Co-Design through Design Brainstorming …................... 15

3.3 Phase 3: Co-Design through Feedback and Re-design $\ldots \ldots \ldots \ldots \ldots \ldots \ldots \ldots . . \ldots \ldots$

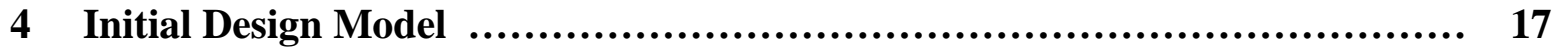

4.1 Stages of Women's Empowerment .................................... 17

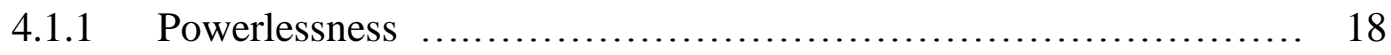

4.1.2 Initiation ................................................. 19

4.1.3 Participation ............................................. 19

4.1.4 Adoption .................................................. 20

4.1.5 Leadership................................................ 21

4.2 NGO Best Practices Applicable to all Stages .............................. 21

4.3 Women's Characteristics Affecting Success Rates ........................ 22

5 Designs for Women's Empowerment in the Developing World ................. 24

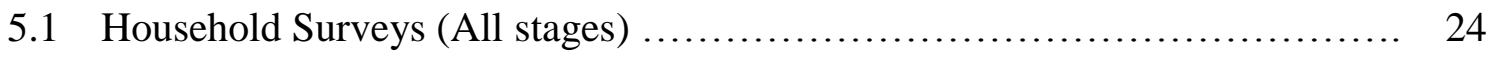

5.2 SMS-based Relationship Building (Initiation stage) ....................... 25 
5.3 Awareness Building Stories (Initiation and Participation stages)............. 26

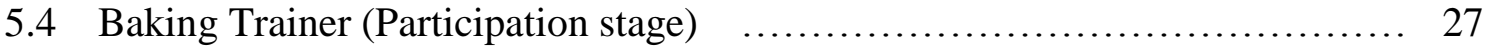



5.6 Morning Reminders (Adoption and subsequent stages) ................... 29

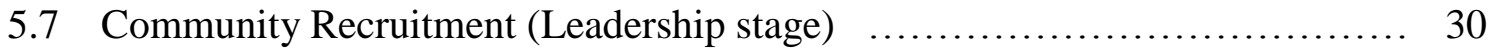



5.8.1 Local Success Stories (Powerlessness stage) ..................... 31

5.8.2 Participant Voting (Powerlessness and Initiation stages) $\quad \ldots \ldots \ldots \ldots \ldots \quad 32$

5.8.3 Progress Monitoring (Participation and Adoption stages) ........... 33

5.8 .4 Summary of Discarded Designs $\ldots \ldots \ldots \ldots \ldots \ldots \ldots \ldots \ldots \ldots \ldots \ldots \ldots \ldots$



6.1 Lesson \#1: Design technologies to involve the entire family in the NGO's

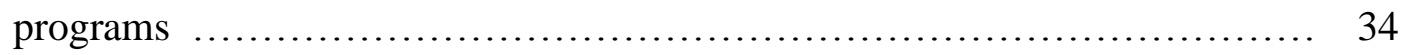

6.2 Lesson \#2: Design technology-aided learning programs such that they

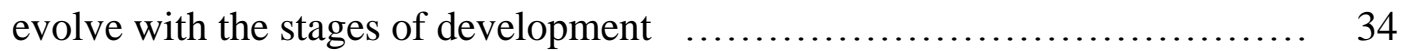

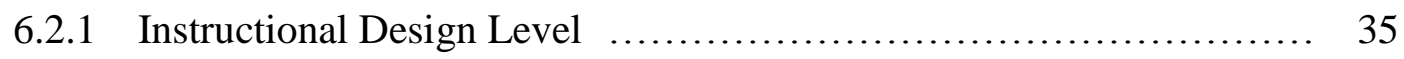

6.2.2 Design to Promote Relationship Building within Communities ....... 38

6.2.3 Design to Promote Holism across Different Stages of

Development

6.3 Lesson \#3: Design for NGO Integration with State, National, and

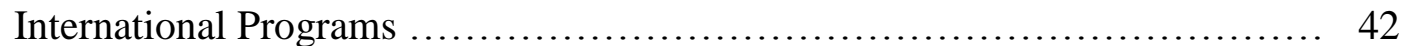

6.4 Lesson \#4: Scope for Overlap in Designs for Women in

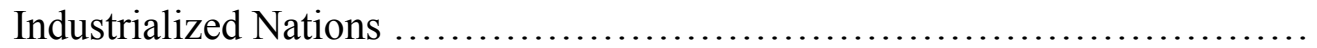

6.5 Lesson \#5: In considering technology platform, keep in mind user's readiness to be proactive 


\section{List of Figures}

4.1 A model for women's empowerment in developing countries based on a 5-stage developmental trajectory. Blue represents passive stages while red represents stages in which women actively take initiative for their own

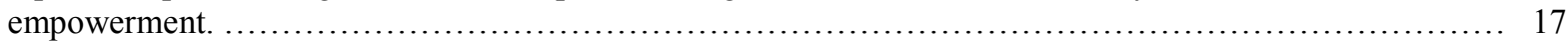

5.1 Staff member enters survey data into mobile application during door to door recruitment (left). Data stored in format readable by desktop spreadsheet applications (right) such as .csv to overcome data entry burden that currently prevents NGO data analysis and review.

5.2 Staff members want an application to be able to send out relevant mass messages of reminders on a regular basis to cell phones accessible to participants from different communities.

5.3 Story shows mother value of getting her baby vaccinated, and how the baby's siblings, father and Anganwadi (local healthcare social worker) play a role in this process.

5.4 Menu of recipes to learn (left), list of ingredients for the recipe (middle), and step-by-step instructions for cooking the recipe (right).

5.5 Menu of children for mother to select from (left). Mobile learning progress reports for that child (remaining screens). Score denotes number of learning modules the child has completed.

5.6 Woman sees menu of women in her group, with morning pictorial reminders each woman has sent her (left). Woman can send pictorial reminder to a woman in her group from a set of choices (right).

5.7 Starter letter in the local language to sing a song from. Help option (question mark) for phone to play out a song, or option to proceed to next letter (arrow).

28

5.8 Staff member selects local past participant success story of a girl, boy, man, woman, in-law, and so on depending on the issue at hand and the stakeholder they want to persuade (left). Staff member can capture new local success story on the field (right).



5.9 Voting application for participants to interact with pictorial images and gain access to messages of developmental topics (left), and automatically send text vote for next workshop topic to NGO staff (right). 30

5.10 Screens from application for women and family members to note which topics they practiced on a given day, and to see their progress report for the week, to realize areas for personal growth.

6.1 Report Card application with Namaste greeting on application start (left), and swastika with diyas visualization of report preferred among illiterate mothers (center). Community Recruitment application with traditional 'bhendi' score bar (okra) wanted by Powerlessness stage women (right).

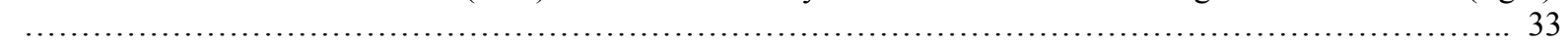

6.2 Report Card application with toned down cultural elements (center and right) preferred among mothers in Adoption Stage, versus cultural diya visualization (left) preferred by mothers in the passive stages. 
6.3 Baking Trainer with the addition of elements to hear precautions (stop sign) and tips (lightbulb).



6.4 Interfaces for women to verify physical change received from a financial transaction with a shopkeeper or autorickshaw driver.

6.5 Awareness Building Stories application with pictures for user to click on to call a women in an advanced stage of empowerment or the local healthcare social worker (left and center). Baking Trainer application with similar elements for user to contact head chef (woman who has reached leadership stage) or NGO staff member (right).

6.6 Community Recruitment application with intermittent screen (center) that asks a developmental question to ponder on, instead of posing a letter to start singing a song from (left, right).



6.7 Screen promoting holism by presenting a menu of different developmental topics.

6.8 Sample situations where women in active stages (Participation, Adoption, Leadership) of empowerment can benefit from ICTs: (a) at home before getting started with the day, (b) at work with other colleagues, (c) on the way to work, (d) at an NGO workshop, (e) in free time at home with other female relatives and neighbors. 


\section{Section 1}

\section{Introduction}

\subsection{Global Gap in Gender Equality}

One of the United Nations Millennium Development Goals (MDGs) is to "promote gender equality and empower women" [1]. Even though the MDGs have raised awareness of problems around gender equity, a recent MDGs Progress Report indicates there remains a huge gap to closing gender inequality throughout the world [2]. For instance, women comprise only 20 percent of non-agricultural employment in South Asia, West Asia, and North Africa [2]. The UN notes that "one-quarter to one-half of girls in developing countries become mothers before 18", and that "out of the world's 130 million out-of-school youth, 70\% are girls" [3]. A UN Secretary General report states that women in the developing world face violence in varying degrees: forced marriage, spousal abuse, forced prostitution, infanticide and genital cutting [4]. Nicholas Kristof, a New York Times journalist who reports widely on human rights issues in the developing world, describes how husbands inflict violence on spouses for disobedience, how parents spend more on healthcare for infant boys than girls, and how women are forced into sex trafficking. Kristof goes on to argue that "in this century the paramount moral challenge will be the struggle for gender equality around the world" [5].

\subsection{Women's Empowerment for Socio-economic Development}

Most importantly, the UN states that gender empowerment is indispensible for achieving the other MDGs [1]. Lessons from developing countries such as China and Rwanda show that improving women's rights not only benefits them as individuals, but also promotes economic development for society as a whole [5]. Specifically, increased schooling for women coupled with social norms that increasingly support their participation in workplaces (i.e. outside home) leads to higher utilization of society's scarce labor resources. Such productivity improvements postpone childbearing, alleviate population pressures, promote higher exports and result in higher incomes $[5,6,7,8,9]$. The latter is significant when in the developing world, "women reinvest $90 \%$ of their income back into their household [e.g. their children's education and healthcare], whereas men reinvest only $30 \%$ to $40 \%$ " [10]. 


\subsection{Research Questions in Designing for Women's Empowerment}

Information and communication technologies (ICTs) can improve lives for women, as well as increase their capacity to contribute to the development of their communities and families (refer to Motivation and Related Work). "Human-computer interaction for development" efforts have targeted domains such as microfinance or maternal health in which women are a primary beneficiary. Despite the magnitude of problems broadly related to gender inequality, there is insufficient focus on examining the needs of marginalized women in developing countries from an angle that goes holistically beyond specific application areas: what are the material and social barriers, including gender biases, which hinder their escape from the vicious cycle of poverty? In the case of non-government organizations (NGOs) who work to promote gender equity, what are the more successful interventions they have employed to overcome these systemic challenges? What can technology designers learn from such interventions? How do we design technologies to complement and even reinforce these grassroots initiatives?

\subsection{Key Contributions and Organization}

After presenting Related Work in Section 2, we address the above questions via field research with 47 staff members in 16 NGOs that work to improve gender equity in India, and 35 lowincome women supported by these NGOs over three phases lasting a total of 15 weeks in the field. Through this research, we aim to learn how the above NGOs improve women's lives in ways that are cross-cutting beyond individual application areas such as health or microfinance, in enabling women to escape the vicious cycle of ill health, illiteracy, unemployment, and poverty, among others. Given the complexity in gender equity issues, this is inevitably a first step. As such, we studied NGOs that focused on educational programs, and have kept more intractable gender-based problems such as sex trafficking outside our scope. Most of the NGOs we interviewed had participant bases of more than a thousand women each, and are highly knowledgeable about the best practices in this field. Our Timeline and Methodology is presented in more detail in Section 3. In Section 4, we present an initial model of the best practices that NGOs already employ so as to identify how the HCI community could design technologies to augment these initiatives that are already effective to some extent. As part of this model, we also present a progression of the women characteristics informed by our interviews. We learned that there is a diverse spectrum in which many women are powerless and needed support, while there are other women who actively sought out personal growth for themselves, their families, their communities and other women. In order to gain feedback from our participants through concrete designs, we conducted design brainstorming sessions with NGO staff members and low-income women. In Section 5, we present discarded designs as well as 7 "proof of concept" prototypes that emerged from our brainstorming sessions, and which we used to conduct subsequent codesign sessions for further insights on the design space. The lessons we gained on designing for this user population through the additional co-design sessions using the prototypes as well as further design directions are presented in Section 6. We conclude with key findings and directions for future work in Section 7. 


\section{Section 2}

\section{Related Work}

\subsection{Feminist HCI in the Industrialized World}

While most women in the industrialized world have access to basic resources, they are still battling to be recognized as equals. Feminist research in the developed world ranges from techniques to recruit girls and women in computing in schools, universities and workplaces [11], to how gender identities are constructed during technology use and video-game play $[12,13]$. However, these situations are vastly different in developing countries, where many women are not allowed to go to school or work outside the home. In other poverty-stricken families, girls undertake child labor and do not have the luxury of time for videogames. In short, in the developing world, women face drastically different challenges, such as unequal access to basic healthcare, education and technology literacy.

\subsection{Feminist HCI in the Developing World}

The following is a review of ICTs that have been used to address basic needs of women in the developing world. Past HCI research in healthcare has used the medium of mobile videos not only to increase motivation among rural Indian health care workers, but also help them to persuade rural pregnant women to use the local health resources available to them [14]. Mobile text messages have also been used effectively in this space of maternal health [15]. Past analysis in India has shown that cable television can decrease a woman's preference for a son as her next child by 70 percent, and the number of acceptable domestic violence situations among women by 46 percent, as compared to women who do not watch cable-television. In addition to domestic violence prevention, this study also shows that there is a corresponding increased school enrollment among the children of women who have cable [16]. ICTs have also improved the employability of women in the developing world. The Grameen Bank has found that their Village Phone Program in Bangladesh "empowered village women economically and socially by reducing and/or eliminating their dependence on other members of their families and giving them increased roles in family decision making," while also enabling women to provide a telephone service to their community members [17]. Parikh's work with the CAM framework that allows for capturing data from paper via mobile phones has helped microfinance institutions and their staff members to better capture the microfinance data of rural Indian women self-help groups [18]. Past work in rural handicrafts and cottage industries has researched whether ICTs can be used for capacity building among women handicraft workers in order to improve their income levels [19]. Other work in this area of employment through handicrafts discusses the varying levels of empowerment among women in Muslim cultures, and reveals that selling hand- 
woven rugs on the internet has not only eliminated middle men in bringing rural women in Morocco increased profits from a world-wide market, but has also empowered the women by enabling them to use the profits for their family and community's welfare [20]. Other works in employment have researched matching domestic workers from slums with middle-class employers in India in preparation for a computerized system for the same [21]. Past work on the basic need of transportation in developing parts of Africa discusses the key role that transportation plays in women's empowerment by providing mobility and access to basic services, and how GIS mapping of gender dimensions around transportation can be used in measuring the progress towards the Millennium Development Goals [22]. Internet-cafes have transformed the lives of women in countries like Egypt, where women claim that the Internet matters in their lives to "1) increase information access/professional development, 2) expand or maintain social networks and social capital, and 3) transform social and political awareness" [23].

\subsection{Design Models and Frameworks for Women's Empowerment in the Developing World}

The above prior work raises our understanding of technology use by women and how to address specific basic needs of women using ICTs. However, many of these efforts have been piecemeal, and have not looked at the big picture of improving lives of the women in a holistic way. They have not considered the women's longer-term professional and personal growth, or how these solutions help women escape the vicious cycles of discrimination, poverty, illiteracy, and unemployment, among others. Given the magnitude of problems associated with women's inequality throughout the developing world, more systematic progress can be made by taking a holistic look at this user population such as to cut across individual application areas: who are some of these women? What are some of their needs, challenges and aspirations? How do these characteristics vary with ascending levels of empowerment? How should we think holistically about designing appropriate technologies to empower them?

In the HCI literature, Bardzell [24] has posed an agenda for feminist interaction design, where she brings up the Feminist standpoint theory by discussing how women in different social settings develop different knowledge, and that this knowledge should be leveraged instead of being marginalized. Bardzell further poses a starter list of feminist interaction design qualities (pluralism, participation, advocacy, ecology, embodiment, and self-disclosure) that should be taken into consideration in feminist interaction design research. In these, she states that feminist interactions designs cannot always be universal, where solutions for the West might not always relate to the developing world. She also argues for collaboration with participants during design, and that this method can help to find a balance between designs that might enforce the beliefs of the designers versus designs that might risk strengthening the existing discrimination on women. She also discusses how feminist designs should ensure gender equity in the ecologies around women, take into account the gender differences in experiential needs, while also enabling users to have a say in how much they want to be affected through interaction with the design. While these design qualities overlap significantly with our approach, we find that the nature of these qualities have to evolve with the growth of the women we studied. We also learned to account for intermediated users [25] and the women's developmental needs. In addition to presenting a 
five stage model and design space, we show how NGO staff, local agents, family and community members can be technology intermediaries for the women, and we flesh this process out in more concrete terms, not just for tasks in the women's daily life, but also for their developmental issues.

In international development literature, there are women's empowerment models such as the Longwe model that UNICEF has adopted [26]. In order of increasing priority for development, Longwe discusses five levels of gender equality - Welfare, Access, Conscientisation, Participation, and Control. Longwe states that higher levels of equality automatically correspond to higher levels of women's development and empowerment. However, it is not a linear model, in that women's Access to items such as land and labor can increase after women have equal Participation in policy making, and after their Conscientisation that gender, unlike sex, is a culturally acquired role that can be changed. As women attain more equality of Control in 'factors of production' and 'distribution of benefits', they can gain more equality in Welfare (such as in food supply, income, and health care). While this model informs priority areas of gender equality to focus on for developmental interventions, this model does not emphasize design directions through more linear scenarios, and does not provide an understanding of the actual external contexts and practical situations faced during grass-roots development work such as the actual stakeholders, intra-family and intra-community social interactions and sociocultural dynamics, organizational best practices harnessed, problems faced at each stage by the stakeholders, and other practical details that are necessary for informing concrete HCI designs in this space of women's empowerment.

Lastly, scholars studying the intersection of ICT and international development have devised metrics and models for evaluating and critiquing the extent to which there are gender disparities in technology access, adoption and benefit [27, 28, 29]. However, [28] mostly considers computer and web-based indicators, while many women in the developing world only have access to the radio, television or cell phone ICTs. In a past study on cell phone usage (ownership and sharing, and mobile relationships) in Rwanda, even though many other cell phone usage indicators did not have significant gender differences, $67 \%$ of cell phone owners among their participants were found to be male [29]. While these analyses, metrics and models for capturing gender disparities in technology use can help in conceptualizing design, they cannot directly inform design.

The contribution of this thesis is an emerging design model that targets women's empowerment in the developing world, so as to enable women to escape the vicious cycle of poverty. We present an initial model of how the characteristics of marginalized women change over a fiveyear period as they grow to realize their potential, the obstacles they and NGOs supporting them face in their struggle to improve their lives, and the NGO best practices for addressing these obstacles. We next present lessons from co-design sessions informed by this model, so as to help the reader better appreciate the subtleties in the design space that this model implies. 


\section{Section 3}

\section{Timeline and Methodology}

We conducted the field research in three phases that lasted a total of 15 weeks with a total of 82 participants. We first interviewed 22 NGO staff about the best practices in their women's empowerment initiatives, after which we engaged in co-design sessions with 25 staff and 35 women supported by our NGO respondents to obtain more feedback that further improves our understanding of designing for women's empowerment and gender equality in the developing world.

\subsection{Phase 1: Needs Analysis (Jan-Mar '10, 11 wks)}

In this phase, our goal was to understand the best practices that NGOs used in grassroots-level initiatives for women's empowerment, so that we can identify opportunities for designing technologies that build on existing successful practices. In total, we interviewed 22 staff members from 12 NGOs. With each respondent, we ran a one-hour semi-structured interview on characteristics of the communities she/he worked with, daily routines of the women in these communities, social relationships within these communities and problems that women faced in improving their lives. Our interviews also focused on NGO staff's daily routines, best practices in their program implementation, and how they evaluate their programs. As each interview proceeded, most NGO staff volunteered information more freely, based on what they felt helpful for enhancing our understanding. On average, we interviewed two staff members per NGO.

This phase was time-consuming because NGO staff were often unavailable due to work commitments, which meant it took repeated reminders to schedule interviews. In selecting NGOs to learn from, we focused on those NGOs with a track record in women's empowerment among low-income communities in India. We were successful in securing these interviews via our primary NGO partner, who spearheaded local women's empowerment initiatives for over two decades and introduced us to the NGOs she highly recommended.

On average, each of the NGOs impacted about 500 women, and 2,000 of their family and community members. Each NGO had been in existence for a minimum of 3 years and had implemented gender empowerment programs for national- and state-level government agencies. Furthermore, 4 NGOs had worked with international non-profits organizations, including UNESCO and UNICEF. We selected staff with at least 3 years of work experience in gender empowerment to interview. With the exception of two administrative staff, all staff members we interviewed interacted closely at the grassroots with their communities. The NGOs assisted with matters such as domestic violence, employability (e.g. adult literacy and candle-making), women's rights, infant-care, and maternal health training. 
We analyzed our data by clustering the NGO responses into affinity groups. It turned out that the women targeted by the NGOs can be clustered into five stages in a developmental trajectory (Figure 1; more in Initial Model). In other words, we organized our findings by these stages after we observed that the beneficiaries have unique characteristics and needs depending on the stage they are in. We also observed that different NGOs worked with women in different stages and had evolved best practices unique to each stage.

\subsection{Phase 2: Co-Design through Design Brainstorming (Jun '10, 2 wks)}

Armed with the analysis of the interview data from Phase 1, including our model that organized needs and best practices according to the stages in a developmental trajectory, we returned to the field. In Phase 2, we explored various ideas for technology designs that targeted the obstacles faced by NGOs in each stage, as well as design ideas for supporting the best practices for each stage. We started by holding 15 half-hour brainstorming sessions (2-3 staff per session) with 7 NGO staff from Phase 1 who were actively involved in all 5 stages, so that we could have perspectives that transcend individual stages. The sessions prioritized on the problems respondents thought to be most important. In brainstorming with the NGOs on solutions to these problems, we tried to sketch out designs to facilitate a more concrete discussion. The NGOs were helpful in giving design ideas, but what was even more valuable was that they voluntarily offered their experiences from interactions with their communities. This contextual information not only informed our designs, but was tremendously useful for enhancing our cultural understanding over our initial model.

Next, we conducted 9 half-hour brainstorming sessions with 11 women from the targeted communities. All interviews with the women were in pairs or groups, except for sessions with women in the Leadership stage, since there were fewer women who had reached that stage. Our participants came from the later three stages in the developmental trajectory who were already proactive in taking steps to improve their lives and possessed cell phones. They could thus contribute ideas, including ideas about mobile applications that aim to benefit them. (The NGOs advised that it was not feasible to engage in brainstorming sessions with women in the first 2 "passive" stages. The latter were beginning to learn about gender biases and that they needed to stand up for their rights.) The 11 women lived in the urban slums and had monthly household incomes below 8,000 rupees (US\$178). The average woman was 30 years old and had five years of formal schooling. The women stitched clothes, embroidered or cooked for a living. Prior to gaining employment (which the NGOs helped with), many of them faced domestic violence because of alcoholic husbands (which the NGOs taught and helped the women to overcome).

\subsection{Phase 3: Co-Design through Feedback and Re-design (Jun-Jul '10, 2wks)}

Our contextual understanding was still limited and could be improved through more interviews, so as to arrive at a more nuanced understanding of the design space. For Phase 3, we developed 12 proof-of-concept prototypes based on the ideas that we brainstormed in Phase 2 with NGOs 
and women in "active" developmental stages. The prototypes were neither intended to be fully functional nor used for usability testing. Instead, the prototypes were meant to express the ideas in a more tangible form to participants, so that we could solicit better feedback. In the discussions, we used 7 of these prototypes as "conversational props" in early-stage co-design [30] to evoke participants into telling us more about their everyday scenarios and how the design ideas would apply (or not). In the case of less complete prototypes, we conducted Wizard-of-Oz studies, since the goal was to assess viability of the applications and to gain further feedback on the design space. The remaining 5 designs out of the original 12 were discarded after two rounds of interviews, since the participants revealed that they were not as practical in their daily lives.

We carried out these conversations with 25 staff members from 8 NGOs who run initiatives similar to previous NGO respondents. Out of the 25 NGO staff interviewed in Phase 3, 18 were new participants whom we had not interviewed in Phase 1 or 2 . To ensure adequate coverage of our model, for each developmental stage, we engaged with an average of 5 NGO staff experienced with that stage. Next, we ran similar 21 contextual interviews with 35 women (28 women came from the urban slums while 7 were villagers; all women from Phase 2 participated in Phase 3) using the prototypes, such that there were 6 to 8 women from each stage. Unlike Phase 2, in Phase 3, we included women from the passive stages. The latter were largely housewives and included rural women, because most women in the passive stage lived in villages and moved to the city to benefit from their new-found employability skills only after reaching the active stages.

Conducting such interviews with women in the passive stages proved to be more challenging and called for more sensitivity. Out of deference to the husbands who head the households, we needed to first show the prototypes to them before women participants felt comfortable talking to us in the former's presence. Next, women in the "active" stages were more familiar with technology (they had cell phones), tried out our prototypes themselves, and volunteered their perspectives more freely. In contrast, we needed to be more proactive in asking women in the passive stages questions. The latter were also less at ease with technology, and hence we spent more time demonstrating the prototypes to them. 


\section{Section 4}

\section{Initial Design Model}



Figure 4.1: A model for women's empowerment in developing countries based on a 5-stage developmental trajectory. Blue represents passive stages while red represents stages in which women actively take initiative for their own empowerment.

\subsection{Stages of Women's Empowerment}

From analysis of the NGO interviews in Phase 1, we observe that women supported by the NGOs appear to progress along a certain developmental trajectory that comprises five distinct stages (Figure 4.1). NGOs estimate a typical woman takes 3-5 years to advance from the first to the last stage.

From among these stages of development, the first two stages of Powerlessness and Initiation are categorized to be passive (marked Blue in Figure 4.1), where women are not aware of the injustice they are facing, and do not speak up for their rights and needs. During these stages, women are just getting to know that they can achieve a better life for themselves and their families, what organizational interventions are about, and why they should attend the organizational interventions. Women passively interact and take part in organizational interventions during these two stages. The remaining three stages of Participation, Adoption, and Leadership, are considered to be active (marked Red in Figure 4.1), where women proactively get involved and seek interaction with organizational interventions, local agents, and other active women in the community. During these stages of development, women are interested in learning how to bring an improved life to themselves and their families, where they can seek help and 
resources, when they can start to achieve this development, and ultimately how they can spread their positive experiences to the broader community.

We found that any stage can be an entry point for an NGO's interventions. For instance, some of the NGOs we interviewed only work with women who actively want to be helped (i.e. stages marked Red in Figure 1), since they believe that sustainability can only be achieved among communities that 'want to be helped', and that this mentality is not something that an organization can plant in the minds of the communities, but should come from within the communities. Many times, this is brought about by the women and/or their families and communities witnessing progress in other nearby communities. This exposure to the possibility of a better life raises curiosity among the members and ultimately drives them to actively seek resources to attain an increased standard of living, and to learn from other communities' best practices in being successful. Many a times, the reason for a particular community's progress was that they were guided by a government or non-governmental grassroots development organization. On the other hand, other organizations claimed that since the women and communities do not have enough opportunities to be exposed to other ways of life, they do not know what a better life can be. Certain relatively newer organizations, worked primarily with women in the passive stages by exposing them to topics around a better life, and claimed that they would grow with the participants, addressing later stages of empowerment when their participant groups would graduate to those levels. Other relatively mature organizations specialized in promoting women to graduate from passive to active stages.

\subsubsection{Powerlessness}

\section{Women Characteristics}

NGO staff claimed gender bias in the home leads to women and girls receiving fewer resources (e.g. food, healthcare and technology) as compared to male and elder female family members. Mothers, as mediators of information between daughters and their husbands, are what NGO staff call a "stopping channel," since they hesitate to advocate opportunities for daughters to the fathers. There is minimal emotional support for women; they cannot freely vent their problems to husbands and parents-in-laws. In some upper-caste families, it is a disgrace for women to work for wages, and so they are confined to the house. Daughters are treated as a burden and temporary responsibility, since their families need to raise money for their dowry. Women are usually deprived from land ownership. They cannot afford items such as cell phones, or risk their cell phones snatched by a male family member if he is annoyed by her use of it.

\section{NGO Best Practices}

For women with characteristics in this stage, NGOs claimed they must be active agents since women and their families are passive about improving the former's lives. In door-to-door visits, NGOs recruit families to participate in NGO programs with help from local agents, or cite community members known to the family who have already benefited from the NGO's programs. NGOs conveyed the benefits to men and parents-in-laws, since their support is 
essential for women's long-term participation in the NGOs' programs (e.g. workshops): "women's empowerment is not just a women's issue, but is everyone's issue."

NGOs address families' apprehensions by giving them an overview of what will be covered during the workshops and what is expected of participants. NGOs also spend time to show that they care (e.g. "how has your day been?") since women have minimal emotional support at home. An NGO staff reflects, "When you become a part of the woman's family, her best friend, her sister, it is then that you (female staff) are motivated even more to bring her out of her problems." Topics that are priorities in this stage are: healthcare (vaccinations, balanced diet, and sanitation), agricultural practices, and making home-made goods.

\subsubsection{Initiation}

\section{Women Characteristics}

This stage is characterized by women deciding whether or not to trust the NGOs, curiosity about what will be covered in workshops, why this information is useful, and women having overcome household resistance to attend their first few NGO events (either with or without husbands and in-laws accompanying). Women are unaware of their rights, the specifics around child rearing, education, health, family planning, sanitation and other developmental topics. At this stage, women are still passive in that they do not actively ask questions, but absorb information which NGOs present to them.

\section{NGO Best Practices}

During this stage, NGOs focus on building relationships with participants to reduce attrition. A personal connection is formed by intermittently cracking jokes, and by conducting workshops near to the women's homes. Women feel comforted at the workshops when they see that other women have similar problems. NGOs convene a series of awareness sessions on different topics to promote a holistic coverage of development. NGOs also hold refreshers to leave the participants with key takeaways to reflect on before the next session. Domains given priority in workshops at this stage are related to more basic needs such as healthcare (e.g. hygiene to prevent diseases, healthy diet to prevent malnutrition, first aid skills during emergencies such as snake bites).

\subsubsection{Participation}

\section{Women Characteristics}

This stage is characterized by the woman trusting the NGO, and her desire to learn where and how to solve her family's problems. The family is usually comfortable with her independent participation in NGO interventions. She actively asks questions to clear doubts during training programs. She seeks help from other participants, staff, and local agents during the sessions, and from local agents such as women and youth groups outside the sessions. 


\section{NGO Best Practices}

Women and NGOs are actively involved in this stage. NGOs hold training workshops more frequently (multiple times a week) on topics such as where and how to exercise their rights, hygiene and child rearing skills, how to use latest technologies in making homemade products, and NGOs provide space as needed for women to practice these skills. Workshops sometimes invite experts who could address more difficult questions. Women forums are run in the community to prevent families from oppressing women. In this stage, NGOs usually restrict their events to be all-women, so they feel women are more comfortable among themselves. NGOs also stimulate women to ponder more deeply on developmental topics through role-playing, Q\&A sessions, movies, puppet shows, films, TV shows, posters, pictures, folk songs, etc. Workshops in this stage focus less on basic needs and more on employability skills (e.g. candlemaking, cooking, sewing, beauty parlor, agriculture, etc), women's rights, education (e.g. sending children to school, adult literacy). A slogan that women repeat at these workshops is: "We don't want to beg - we just want our rights! We want to make a change in our lives! We'll make our lives successful ourselves!" In this way, NGOs attempt to provide as many platforms and resources that can facilitate active participation and learning among women in this stage.

\subsubsection{Adoption}

\section{Women Characteristics}

This stage is characterized by the woman having internalized knowledge about developmental topics such that she can accrue benefits to herself and her family. She has started to gain more freedom and respect - both within and outside her family, since they have started to see the fruits of her work. One NGO staff boasts: "Fathers get sensitized after seeing the fruits of NGO efforts - education gains, girls getting jobs, lowering dowry, women's products getting sold. It's not just the woman, but the welfare is happening to the whole family." Her routine has become very busy since she has to balance work with household chores. She can afford to purchase her own items, such as a cell phone, since she is economically self-sufficient.

\section{NGO Best Practices}

While NGOs continue to hold regular events for women to voice their needs and help them solve their problems, at this stage, NGOs begin to take a passive role by not offering help on a daily basis, since they want the women to take charge of their lives in the absence of regular supervision. When women want to learn new things, they also know where to seek the training resources. Workshops at this stage focus on helping women grow financially (e.g. microfinance, employability skills, sales and marketing). With these best practices, NGOs have encouraged women to take an active role in supporting their daughters' further education: "Girls have started going $20 \mathrm{~km}$ away from home to college. Previously, daughters would not be allowed to pursue 
higher education because colleges are far from the village. After our initiatives, mothers now force fathers to take daughters by motorbike to college."

\subsubsection{Leadership}

\section{Women Characteristics}

In this stage, a woman can now ensure she and her daughter (i.e. a "next generation" woman) are not discriminated against in benefits, and knows how to access economic, social and political resources. Women join local women groups as well as share positive experiences with women in earlier developmental stages. A subset of women in the Leadership stage undergoes training to be local social workers, political leaders, or NGO staff. The woman in this stage is a leader at the individual, family and community levels.

\section{NGO Best Practices}

In this stage, NGOs play a passive role and offer support only when women or their families seek help. Usually, there is no need for NGOs to help since the woman is now independent and can in fact support women in earlier stages. The latter, who are seeking a better life after seeing positive examples in their community, will seek help from experienced women in the Leadership stage, their families and local agents. Topics most relevant when women seek additional growth are those related to training to become a local politician, nursery school teacher, government social worker, NGO staff member, among others.

\subsection{NGO Best Practices Applicable to all Stages}

In addition to the above stage-specific characteristics and practices, there are certain best practices that established NGOs strive to harness at all stages, since they have more financial, human, and administrative resources.

- NGOs ensure that there is/are clear intervention goal/s and evaluation criteria: Staff members aim to define a theme based on people's needs, and think of desired after effects (outcomes), after seeking input from local people. They feel it is important to conduct evaluations and monitoring during and after the intervention. They also have staff from different disciplines such as engineering, social work, policy, and other fields as well as local people involved during intervention planning to ensure a more comprehensive theme and planning.

- NGOs integrate interventions into other local to national programs, and broader international movements: Staff members try to align with strategies and schemes at all levels. This helps all simultaneous efforts make more progress, for a larger developmental impact. They hold interventions around local, state, national, and international holidays, and keep up with local to international issues through readings, 
seminars, and gatherings. They also influence the decisions and policies of higher up bodies at the state, national and international levels by citing their local field successes.

- NGOs work closely with "local agents": NGOs work closely with local members of the community, commonly referred to as local agents, who usually include at least 1-2 local individuals, who have been trained by the organizational staff on specific intervention aspects such as recruitment, needs gathering, cell phone usage and other such aspects relevant to communicating remotely with the staff members and spreading word to the local community. These local agents also include local women groups, local teachers, local musicians, local shopkeepers, local youth groups, local government social workers, local political or religious leaders, and/or other respected and trusted individuals in the local community. Proactive and vocal participants during the NGO's first few initiatives with the community usually form the initial members of this local agent pool. NGOs hold motivational interventions when training the local agents, and give freedom to the local agents to express themselves and share personal stories during training and planning, so they can motivate each other. They communicate via cell phone with the local agents on a weekly basis, enabling local agents to help with planning, announcements, and recruitment. They also have local agents provide a platform to the villagers to voice their demands and needs, and to find out the problems of the women and their families to ensure participant driven interventions. Their involvement also helps the local agents feel more respected in their village. They start making a name for themselves in the village, which makes them feel empowered and helps build their self-confidence. Many NGOs claim that the involvement of such local agents helps interventions reach more selfsustainable stages.

- In cases of group events, NGOs ensure the events are manageable and engaging for all: NGOs keep interventions down to 20-50 participants. Many times the government officials/police will stop efforts if the groups are bigger than this. Some NGOs also keep interventions down to 10-20 people for a group size that is manageable for one conductor and to also foster an informal environment. They keep the intervention duration short. That is, interventions should not be too long (over 1 hour), or they claim that the participants get bored. They also give priority to changing the instruction medium every 10 minutes, so as to keep the intervention engaging for the participants.

\subsection{Women's Characteristics Affecting Success Rates}

While NGOs reported that they have improved the lives of thousands of marginalized women and their families, their best practices have usually not been evaluated rigorously since program implementation often takes higher priority. The implication is that the model presented in this section is a starting point for further research. While there are many successes with women in the active stages, usually less than $50 \%$ of the women in passive stages graduate to subsequent stages. NGOs told us that the starting stage and graduation success rates also depend on women's characteristics such as those listed below. 
- Proximity to urban centers: NGOs claim that women living closer to the city usually have more exposure to other ways of life and consequently face less inequality in their daily lives than those farther away from the city.

- Initial income: NGOs claim that usually more economically stable families will have more resources, and consequently, women are less likely to be discriminated in aspects such as healthcare or food distribution.

- Caste: Women from scheduled tribes and lower castes such as Dalits and Adivasis are treated more unfairly by the community than women from upper castes. However, family prestige issues such as not being able to work outside the household do not always hold for women from these communities, because of the corresponding higher rate of poverty in these families and already existing inferior family status, placing them at higher stages of empowerment. On the other hand, in some cases, upper caste families do not allow women to work outside the home. However, unlike their experiences with upper-caste women, many NGOs state that there is a need to conduct more capacity building among lower-caste communities, and they have yet to build a set of best practices among women from these communities. This is because upper caste women are usually not allowed by their families to take part in organizational interventions that lower caste women also participate in. Many organizations focus more of their efforts on upper-caste socioeconomically deprived women, because of the greater overall community support from local officials and religious heads to make their interventions in those communities sustainable.

- Family structure and dynamics: NGOs claim that in joint families, women have to seek approval from male and elder female members of the household for daily decisions, while this is less prevalent in nucleus families. In nucleus families where an alcoholic or disabled husband does not work, the woman has to work to earn for the family, setting her off at a higher level of empowerment. On the other hand, in larger families there are in-laws and children to help out with domestic and other daily tasks, which can assist women in later stages of empowerment. NGOs further state that in the case of women facing more socially and physically challenging issues at home, such as domestic violence, the rate of graduation along the five stage trajectory is usually slower.

- Age of woman: While elder women have less of a hierarchy above them, NGOs feel younger women may be more vulnerable to discrimination within the family in situations such as access to resources and in decision making, which may delay their progression to later stages of empowerment.

Additional characteristics that affect the starting stage and graduation success rates of a woman include illness in the woman's family, available local infrastructure, religion, and cultural practices, among others.

Nonetheless, a recent government study estimates there to be 3.3 million NGOs in India alone, revealing that there is at least one NGO for every 400 persons in India, which is still a lower bound since NGOs may be registered under other Acts than what the study accounted for [31]. By designing ICTs to complement the best practices and to solve the challenges faced by such grassroots organizations, there is potential to benefit millions of women, their families, and communities in the developing world. 


\section{Section 5}

\section{Designs for Women's Empowerment}

In this section, we present the initial design ideas from the brainstorming sessions with NGOs and urban slums women in Phase 2. We emphasize the cultural factors that motivated the designs rather than the designs themselves. We believe a focus on the former enables better appreciation of the design rationales and design space. In total, we came up with 12 designs, but only retained 7 of them for subsequent co-designs because the others turned out to be less practical.

While only 4 NGO staff members used desktop applications at work, all of them used computers for personal purposes. All of them owned cell phones, which they used at work for communicating with colleagues, organizing workshops and meetings, and so on. For these reasons, our designs focused on the cell phone and desktop platforms.

We also noticed that the co-design brainstorming sessions with women respondents appeared to empower them by giving them a voice; the sessions gave them the opportunity to voice their problems, needs and dreams, and to express their hopes that these aspirations will be fulfilled in the near future.

\subsection{Household Surveys (All stages)}

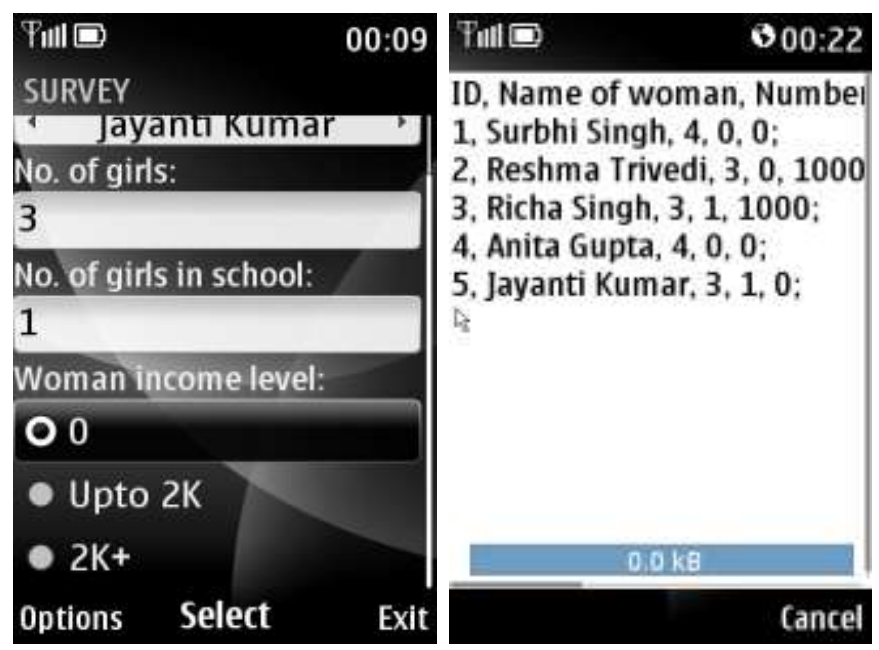

Figure 5.1: Staff member enters survey data into mobile application during door to door recruitment (left). Data stored in format readable by desktop spreadsheet applications (right) such as .csv to overcome data entry burden that currently prevents NGO data analysis and review.

In all stages, NGO staff consistently indicated that program implementation takes higher priority than evaluation. NGOs as such claim that the lower emphasis on evaluation is a key obstacle to 
understanding the impacts their programs have and how to improve them. Data collection is the first step. Existing data collection efforts begin during door-to-door recruitment visits, where NGOs currently record data about families (contributions by husbands vs. wives to household incomes, number of daughters vs. sons in school, etc) on paper to keep track of the households they visited. This data is then entered into spreadsheets when NGO staff members return to their offices. This data entry step is especially cumbersome since there is data from dozens of participants in a single workshop. Less-established NGOs skip this step since more resources are allocated to program implementation, even though baseline data from such surveys can inform NGOs on which programs (both new and ongoing ones) are most appropriate. Since existing surveys involve multiple-choice and numeric responses, a survey application on a cell phone is feasible (whereas text input is difficult on cell phones). We designed such a survey application shown in Figure 5.1.

\subsection{SMS-based Relationship Building (Initiation stage)}

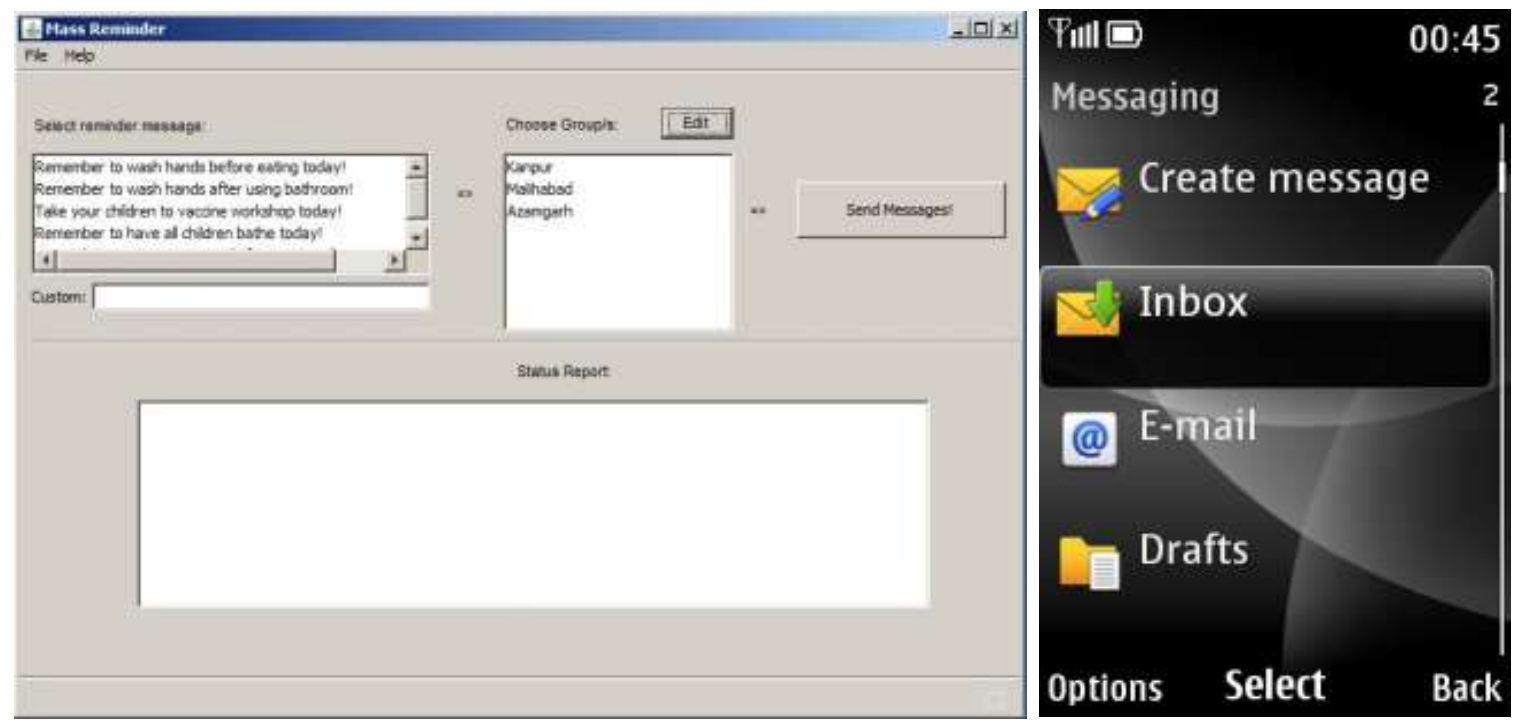

Figure 5.2: Staff members want an application to be able to send out relevant mass messages of reminders on a regular basis to cell phones accessible to participants from different communities.

During Initiation, a best practice is for NGOs to strengthen relationships with their communities to facilitate continual, active involvement in NGO programs. However, due to the huge numbers of beneficiaries, NGO staff members have almost no time to interact with their communities between visits. We designed a desktop-based application (Figure 5.2) that NGOs can use to keep in touch with their local agents and communities more regularly via text messages on cell phones. Messages can be reminders about NGO events (eg: "agricultural workshop at 5pm in front of village chief's house") or material covered in the last workshop (eg: "remember to wash your hands after using the bathroom"). While the women are semi-literate, texting is nevertheless feasible because their husbands are literate and can pass on the message. This application builds on another best practice for Initiation, i.e. NGOs need to target families as a whole and not exclusively women only. 
In the NGOs' experience, since women are so caught up in their chores and childcare matters, earlier reminders are forgotten by the next day, which is why the application has to support the broadcast of event reminders on the same day they are held. NGO staff were excited about this design: it can help women and their families feel more connected to the NGOs, act and reflect on knowledge acquired during the workshops, and hence see short-term benefits of applying this knowledge. NGOs expect the latter to motivate women and their families to attend more programs, and graduate sooner into subsequent developmental stages.

\subsection{Awareness Building Stories (Initiation and Participation stages)}
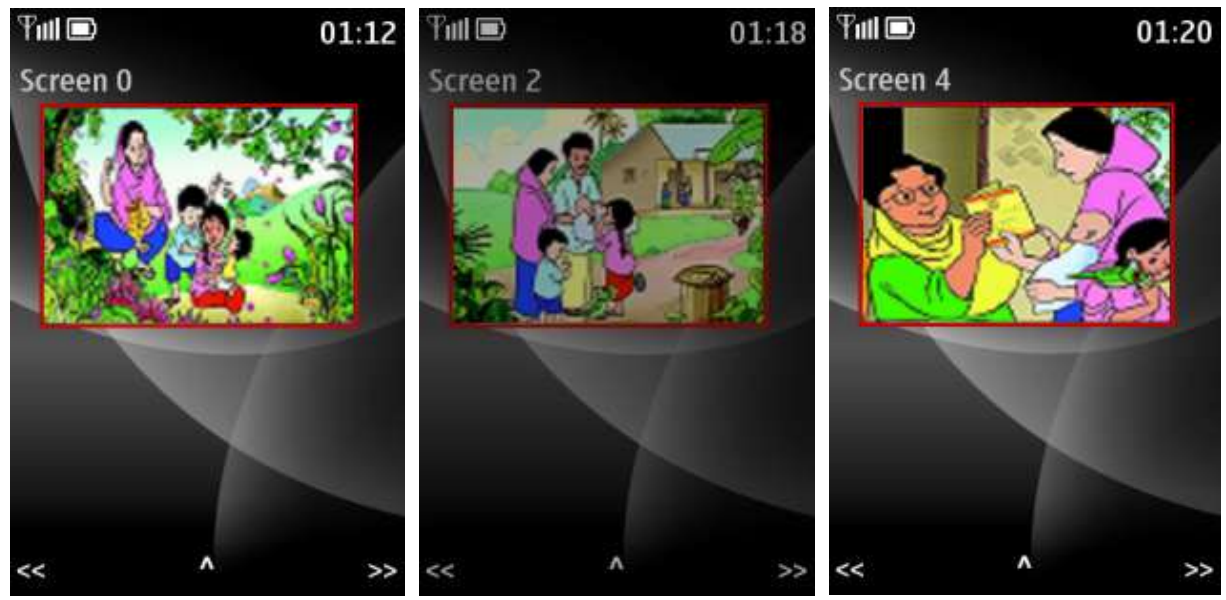

Figure 5.3. Story shows mother value of getting her baby vaccinated, and how the baby's siblings, father and Anganwadi (local healthcare social worker) play a role in this process.

One of the NGO best practices during Initiation is to give women enough time to assimilate and reflect on what they learned in a workshop, during the interval (usually a month) before the next workshop (where a new topic is covered). It is easy to forget the details of what was covered, and since the women are semi-literate, they cannot take notes during workshops. NGOs claimed this problem severely impedes the women's learning. We learned many NGOs already use, in workshops, the Meena Awareness Building Stories developed and distributed by UNICEF on paper handouts [32]. The stories revolve around the character Meena in narratives that raises awareness on gender-related topics (e.g. the value of taking one's baby for vaccinations and the role that husbands can play to complement their wives). While existing stories are conveyed in a comic form, they are paper-based and require NGO staff to narrate.

We designed a cell phone application for women to access similar stories and narratives in the absence of NGO staff. Mothers and NGOs liked this idea; the former could review content from the workshops in the mothers' free time in the afternoons. Infant-care mattered most to the women we interviewed. We therefore adapted a Meena story on this topic into digital format (Figure 5.3) and presented it for feedback in Phase 3. An important step was to adapt the original story from the mother character's point of view and voice (it is currently from the daughter's point of view), so that mothers can better relate to it. 


\subsection{Baking Trainer (Participation stage)}
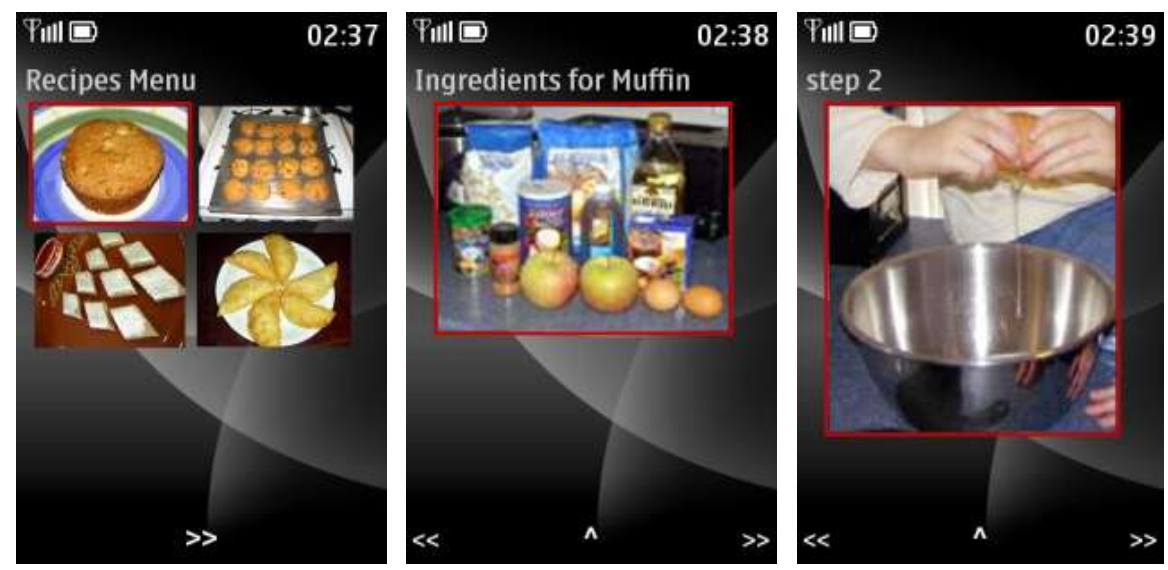

Figure 5.4: Menu of recipes to learn (left), list of ingredients for the recipe (middle), and step-by-step instructions for cooking the recipe (right).

One of the best practices is to enhance vocational skills, one of which is to cook for a living. The NGOs and women told us they catered food for international companies and five-star hotels located nearby. Their market research showed there is a huge demand for baked food (e.g. muffins) in the Indian catering market; hence they wanted to learn to bake such food. NGOs currently teach how to prepare such food with actual demonstrations at workshops. The recipes were often adapted for the women's kitchen, whose cook stoves and other cookware differed from Western kitchens. These workshops suffered from the same drawbacks as the above Meena comics in terms of retention and low-literacy.

We designed a mobile application for baked recipes with local language voiceovers to help the women learn new recipes at their own pace, as well as review food preparation steps and ingredient lists (Figure 5.4). 


\subsection{Report Card (Adoption and subsequent stages)}
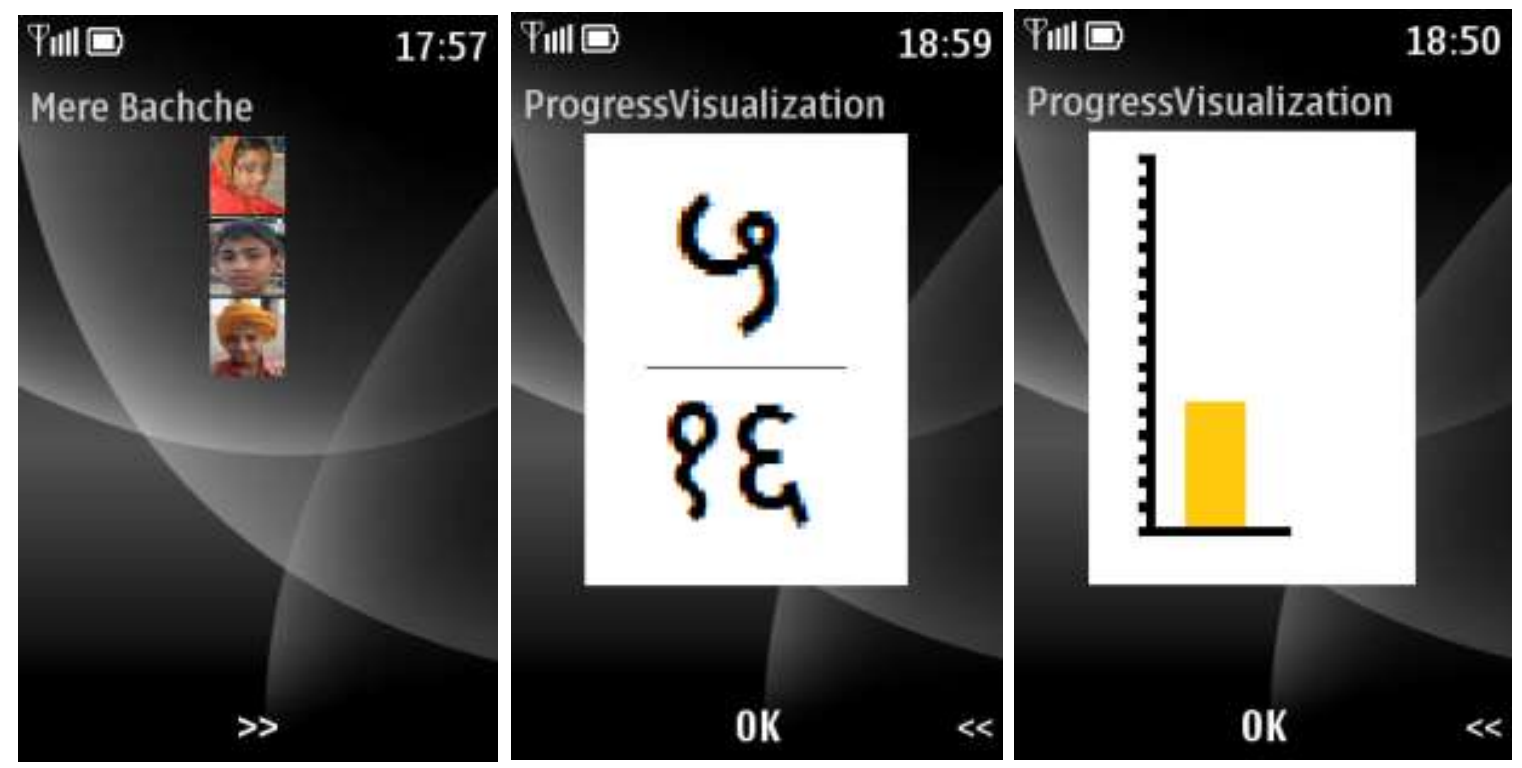

Figure 5.5: Menu of children for mother to select from (left). Mobile learning progress reports for that child (remaining screens). Score denotes number of learning modules the child has completed.

Mobile learning for low-income children in the developing world has demonstrated promising educational gains [33]. Poor parents are also increasingly enrolling their children in private schools that charge affordable fees (about US\$2.5 per month), as an alternative to public schools, if they can afford (likely for mothers in Adoption stage), since private schools are more accountable. This research project initially started as an effort to understand the involvement of mothers in their children's mobile learning. However, after discussions with NGO staff members, it became clear that maternal involvement would be feasible only once women acquired a higher level of empowerment themselves first.

We designed an application for women in the Adoption stage that reads mobile learning application logs and displays a child's progress as a report card on the cell phone (Figure 5.5). This application enables mothers to be more involved in their children's education. Mothers said they will use it to encourage their children to complete their mobile learning classes. They also said they were more interested in viewing summary data (e.g. number of course modules completed) than details (e.g. performance on individual modules), which they cannot understand. 


\subsection{Morning Reminders (Adoption and subsequent stages)}

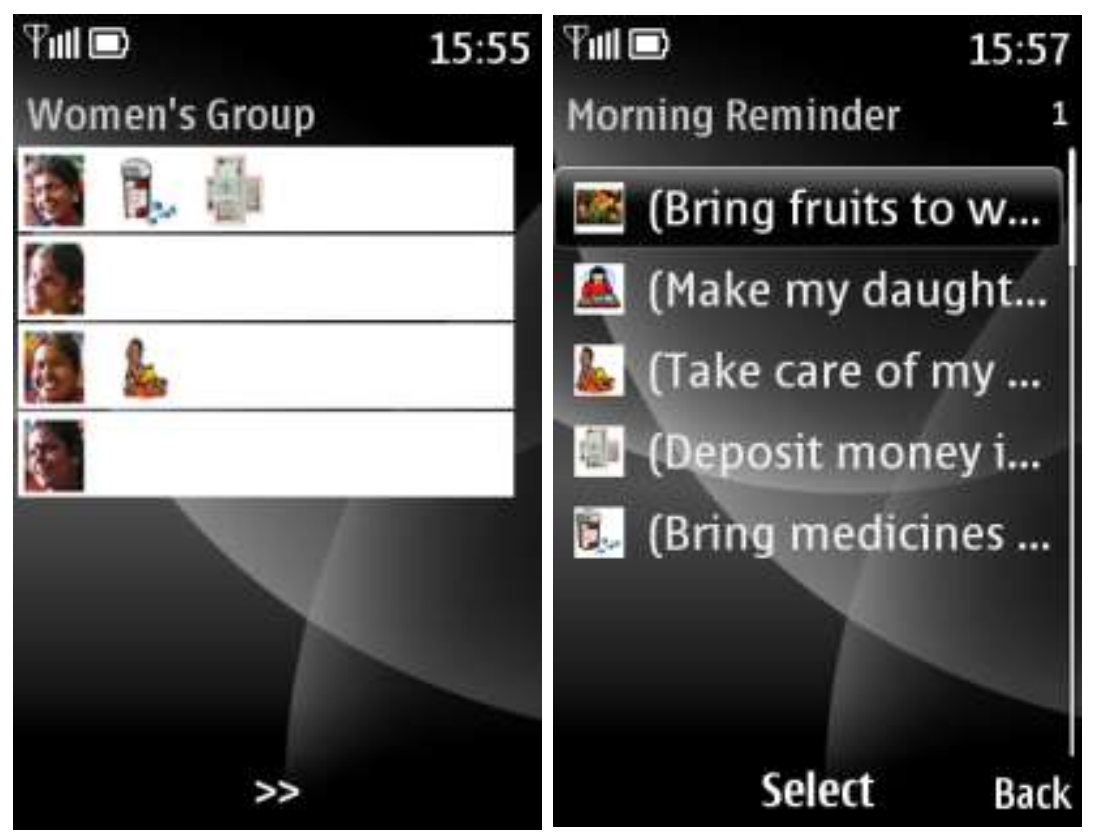

Figure 5.6: Woman sees menu of women in her group, with morning pictorial reminders each woman has sent her (left). Woman can send pictorial reminder to a woman in her group from a set of choices (right).

Women mentioned that their work-life schedules become hectic in the Adoption Stage. NGOs claimed that women new to this stage struggle to remember their deadlines and tasks for the day, such as what items to craft or which ingredients to purchase on their way to work.

In line with the best practice that women in this stage should strive to be independent and help one another (vs. relying on NGOs, unlike the above SMS application), we co-designed application interfaces that women could use to send multimedia reminders to one another (Figure 5.6). Women told us they liked this application, since they felt it not only could help them to remember their commitments but also show one another their support through mutual reminders. 


\subsection{Community Recruitment (Leadership stage)}
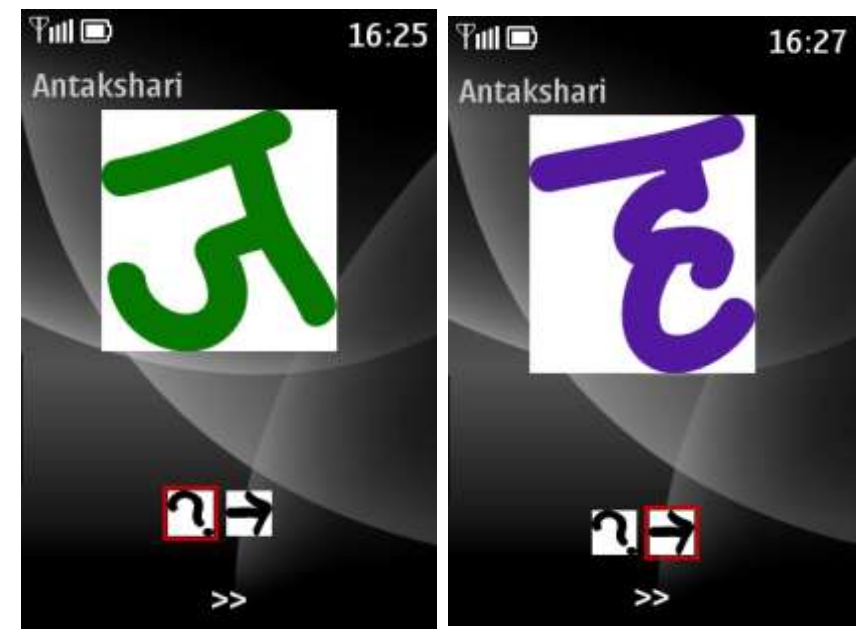

Figure 5.7: Starter letter in the local language to sing a song from. Help option (question mark) for phone to play out a song, or option to proceed to next letter (arrow).

Women in the Leadership stage can be effective agents for recruiting other community members to participate in NGO programs. The women are already known and trusted by the community, and can invite community members in groups rather than approach them door-to-door. However, women in the Leadership stage are only learning to give workshop talks on developmental topics, and could benefit from tools to do this.

Since community members said they often watch television game shows (e.g. Antakshari, a traditional game in India where a team sings a song based on the last letter of the opposing team's song, or lose a point) and play similar games with neighbors and family members, we designed a mobile game that plays Antakshari songs on developmental topics (Figure 5.7). Women said the informal game setting and content presentations via the cell phone makes them less nervous about having to describe the benefits of NGO initiatives to community members in their recruitment drives.

\subsection{Discarded Designs}

We decided after two rounds of interviews not to proceed with these designs. This was because they were not feasible for the stage of empowerment we had developed the designs for, and with slight modifications they would not meet high priority needs of other stages either. More fleshed out discarded designs are noted below. 


\subsubsection{Local Success Stories (Powerlessness stage)}

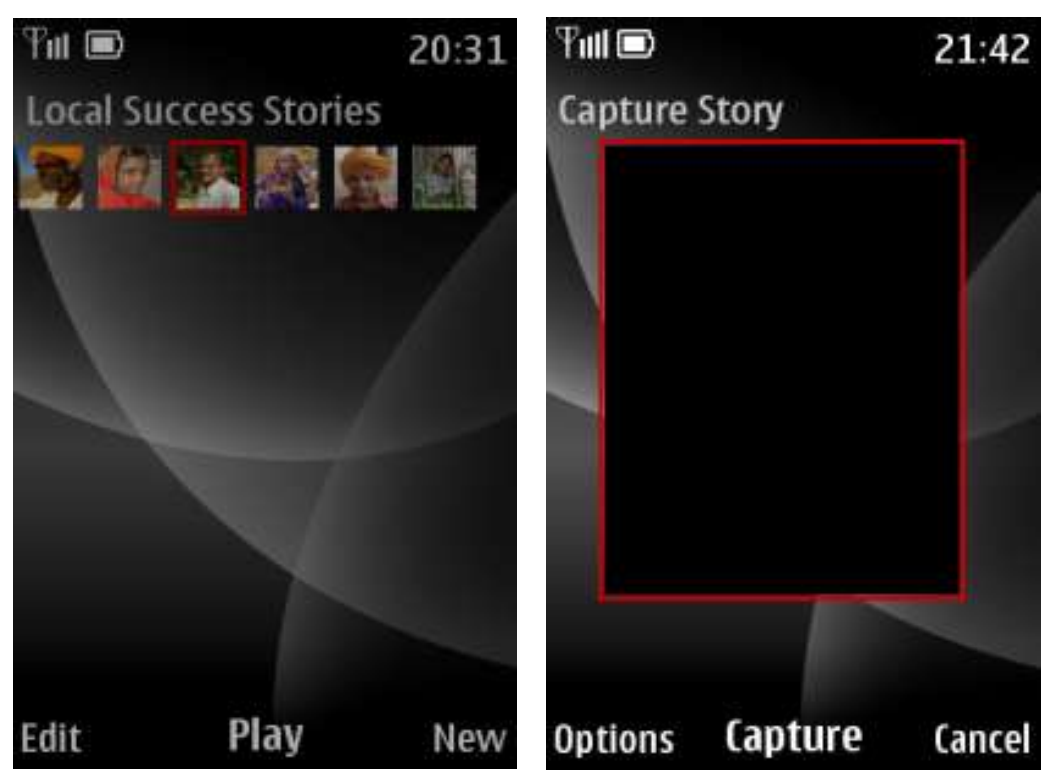

Figure 5.8: Staff member selects local past participant success story of a girl, boy, man, woman, in-law, and so on depending on the issue at hand and the stakeholder they want to persuade (left). Staff member can capture new local success story while on the field (right).

NGOs claimed less than half of the women they approached during their door-to-door recruitment eventually joined the NGO initiatives. Since women and their families initially viewed these initiatives apprehensively, a best practice is for NGOs to build interest by sharing stories of local community members (whom the former know) who have achieved success through the initiatives. We designed a mobile application that NGOs can use during door-todoor visits to showcase and record images or videos of local participant stories (Figure 5.8), such as a mother describing that her children have not fallen sick since they started washing hands more often.

However, during door to door recruitment, NGO staff wanted to retain their personal touch and best practices of cracking jokes, telling stories with self expressions and hand gestures, and changing their techniques based on the body language that they judged of the participants, without technology interfering with or replacing their existing efforts. While using images or videos of male or local success stories or playing videos of trailers on their cell phones can be useful for recruitment, many staff members claimed that they viewed the cell phone as an individual-based technology. They felt there is not enough screen space for a cluster of individuals to see an image or listen to a video on a cell phone, which is usually the case during their door-to-door visits. Instead of using the cell phone based success stories for all of their door-to-door participants, they felt that it could be used only in cases where they may need more resources to convince fewer members of the family (usually where the male members of the household are very rigid about not allowing the women in the household to get involved). However, since they need to collect data from all households they visit, instead of the success stories which they could narrate themselves being given priority, they wanted the Household 
Survey application discussed above to be given priority in brainstorming applications for this stage.

\subsubsection{Participant Voting (Powerlessness and Initiation stages)}

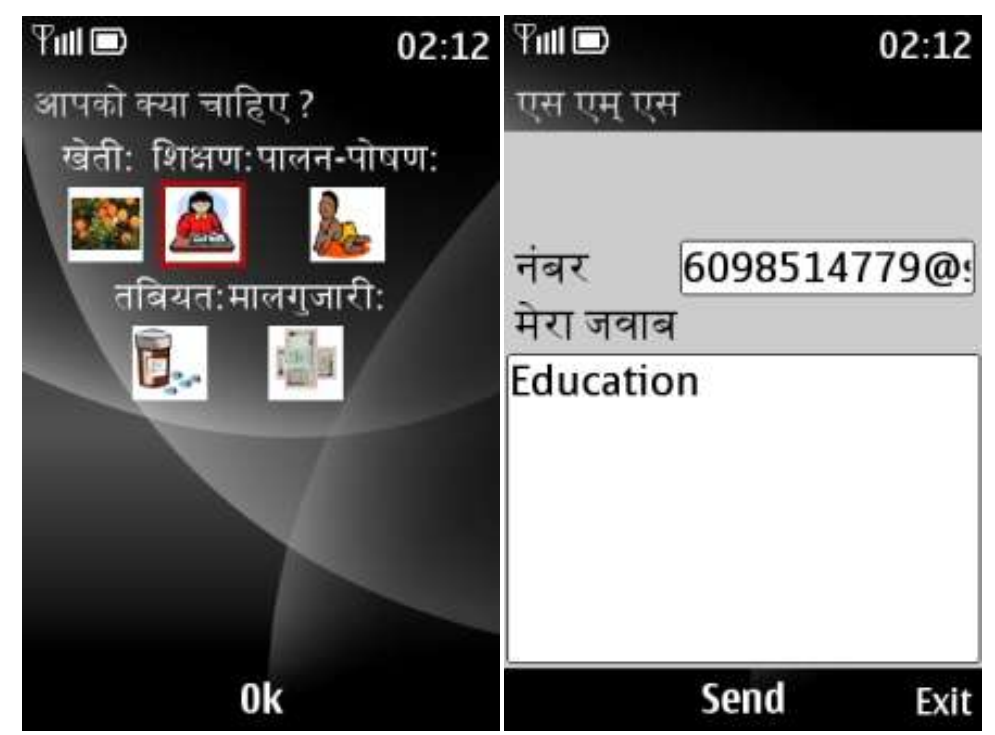

Figure 5.8: Voting application for participants to interact with pictorial images and gain access to messages of developmental topics (left), and automatically send text vote for next workshop topic to NGO staff (right).

More established NGOs claimed that one of their best practices is to involve the participants in identifying workshop and interventions topics, based on what participants want to learn. To complement this best practice, we designed a Voting application (Figure 5.8), where participants in earlier stages of empowerment could explore workshop topics by interacting with pictorial images of developmental topics and gain access to their respective audio messages, and could send NGO staff and local agents their choice for the next workshop topic on clicking an image.

However, NGOs claimed that such an application required active participation too soon for women in the Powerlessness stage where they are still getting educated about the purpose of getting involved, and are still passively interacting with NGO and local staff members. NGO staff also felt that an individual-based voting application would further hinder already less likely participant interactions with local agents and other community or family members in brainstorming together for the next workshop topic; a process which NGOs feel can actually strengthen relationships among the family and community members in earlier stages of empowerment and motivate the families and/or community as a whole to progress to later stages of empowerment. While NGO staff felt that such an application might apply to women and families further along the developmental trajectory who have already built a fairly strong community, training applications for later stages took precedence among the staff and women participants. In addition, at this point women already meet the agents directly on a daily or weekly basis, so they felt they could do a quick in-person poll instead. 


\subsubsection{Progress Monitoring and Sharing (Participation and Adoption stages)}

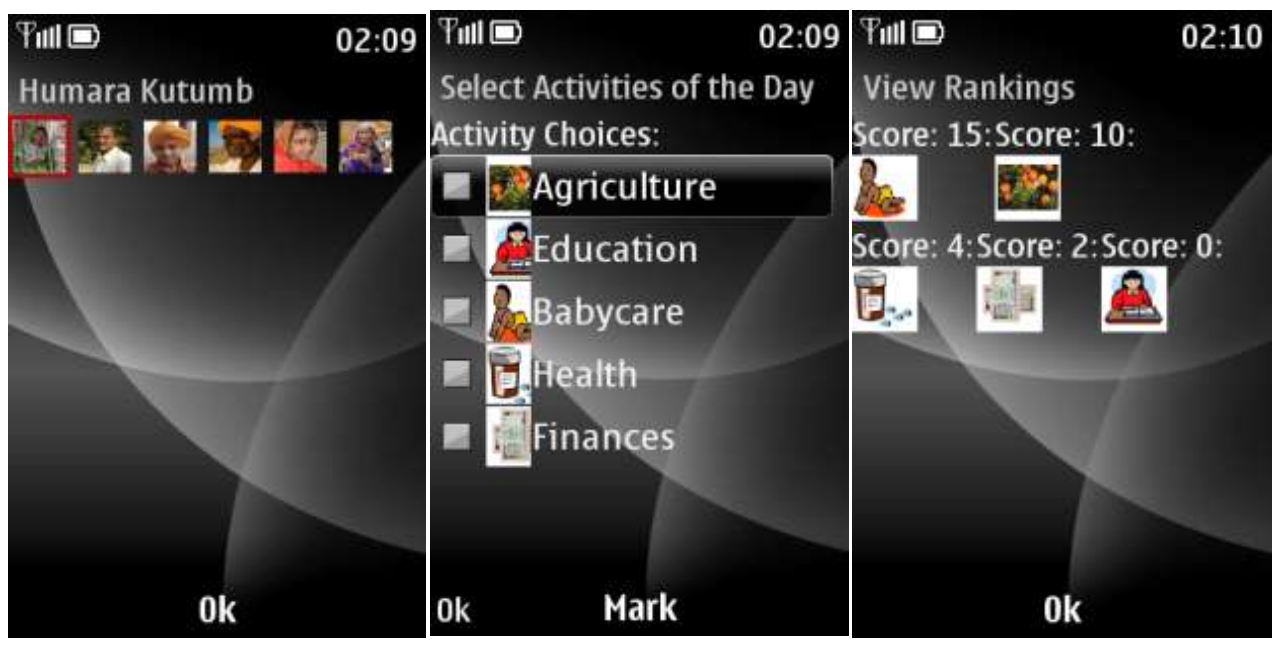

Figure 5.10: Screens from application for women and family members to note which topics they practiced on a given day, and to see their progress report for the week, to realize areas for personal growth.

The pictorial progress monitoring application (Figure 5.10) was designed for women to realize areas for further improvement, and to also share their daily developmental activities and progress with each other and their family members, in order to keep them motivated to continue with their learning.

However, we found that women don't have enough time to spend on using technology during the Adoption stage, and need applications that will motivate them while also increasing their efficiency, such as the Morning Reminders application discussed earlier to remind each other about their tasks. While this application could be used during the Participation stage, there was a higher priority to undergo training and the participants felt more secure to stay in touch with the head agent or staff member rather than disclosing any private involvement, learnings or progress with other women or family members.

\subsubsection{Summary of Discarded Designs}

Other brainstormed designs included a Family Progress Monitoring application (similar to the Progress Monitoring application) for all family members to monitor their activities together, an event Trailers application (similar to the Local Success Stories application) for NGO agents to use during recruitment efforts to show participants what happens at NGO events. However, these applications were also discarded for similar reasons as listed in the above sub-sections. To summarize, these and the above designs were discarded for reasons such as jumping the Passive/Active boundaries to soon, replacing a best practice with technology as opposed to complementing it, the low benefit of technology intervention over other methods, the lack of participant or family interest in using the application, security and privacy issues that concerned the women, and/or the relatively low priority for the application compared to other needs in the women's developmental stage. 


\section{Section 6}

\section{Phase 3 Findings: Lessons for Design Model}

The above designs were implemented and the resulting proof of concept prototypes were used as "conversational props" with NGOs and women in Phase 3 to explore the design space for operationalizing NGO best practices using technology. Although this section also presents redesigns to some of the above designs, we believe what is more important are the sociocultural findings evoked using the prototypes that illuminate the design space further.

\subsection{Lesson \#1: Design technologies to involve the entire family in the NGO's program}

In co-designing the SMS Relationship Building application with NGOs, the latter opined that putting husbands in the position to relay text messages to their wives helps to make them feel included in the NGO programs. As a result of not being bypassed, husbands will be more inclined to lend their support to their wives to attend the programs on their own. This is in line with the best practice of enlisting the support of male family members in order to create a home environment that is supportive of women's participation in NGO initiatives.

Similarly, in the case of Report Card, women told us they would not only be empowered to encourage their children to complete all their learning modules, but would also like to share their children's scores with other members of the household such as parents-in-law. The women are excited that the prototype allows them to take control of something (in this case, their children's education) within the family, while also involving the family in the children's education, so as to nurture an even more supportive environment for one another's well-being.

\subsection{Lesson \#2: Design technology-aided learning programs such that they evolve with the stages of development}

As women progress through the stages of development, they have changing educational needs and, consequently, changing design needs. At the instructional design level, women at higher levels of empowerment showed a decreasing need for cultural and entertainment elements and an increasing interest in educational content as opposed to women in earlier stages of empowerment. Women at higher levels also showed a decreased need for scaffolding supports. In addition, NGOs and women showed the need for designs to increase communication and improve trust between different social groups at each of the stages of empowerment, by improving women interactions with NGO staff and family members in earlier stages to interactions with other women and community members in later stages. NGOs also voiced the 
need for designs to help women in realizing connections between various developmental topics when they review material from past educational workshops, as they progress through the stages of empowerment.

\subsubsection{Instructional Design Level}
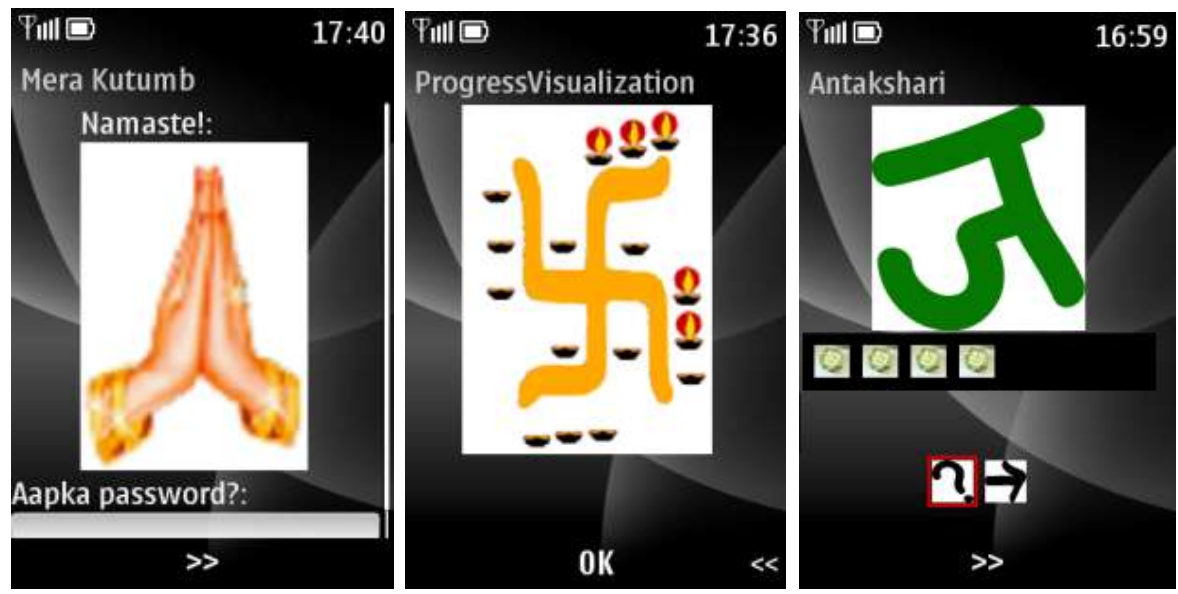

Figure 6.1: Report Card application with Namaste greeting on application start (left), and swastika with diyas visualization of report preferred among illiterate mothers (center). Community Recruitment application with traditional 'bhendi' score bar (okra) wanted by Powerlessness stage women (right).

\section{Support Evolving Priorities for Cultural and Entertainment Elements}

We incorporated cultural elements into our application designs so as to make them more culturally relevant. For instance, we had a voiceover for a cultural greeting (e.g. "Namaste!") at startup time (Figure 6.1). We observed that women, especially those in the Powerlessness and Initiation stages who do not have cell phones, reacted to this greeting by placing their palms together in the Namaste posture. Given their low levels of exposure to technology, they told us that this cultural element in the prototype made them less afraid of the cell phone as a device to interact with. Fear of technology is commonly reported in the HCI4D literature [33], especially among the lowly educated, for reasons such as nervousness about damaging the device. Our findings suggest cultural design elements can reduce such barriers. In addition, for the Community Recruitment application, women in the Powerlessness stage (women to be recruited) wanted a 'bhendi' (bhendi is okra, which is a traditional symbol used for negative scoring whenever a team cannot come up with a song on their own) to be added to their negative score, whenever the help option is used in the game.

In reviewing our educational prototypes such as Baking Trainer and Awareness Building Stories, NGOs commented that women in the passive stages had more free time than women in the active stages, and hence watch television programs such as Balika Vadhu (soap opera on child marriage) and Bollywood movies like Swades (a village becomes self-sufficient in electricity as a result of a community effort). NGOs told us that although women in the passive stages watch such programs for their entertainment value, the programs also have a side-effect of raising viewer awareness on educational issues, including developmental topics. By implication, similar 
entertainment aspects (e.g. the comics and engaging storyline in Meena stories) are critical for making training materials more appealing to women in passive stages of empowerment.
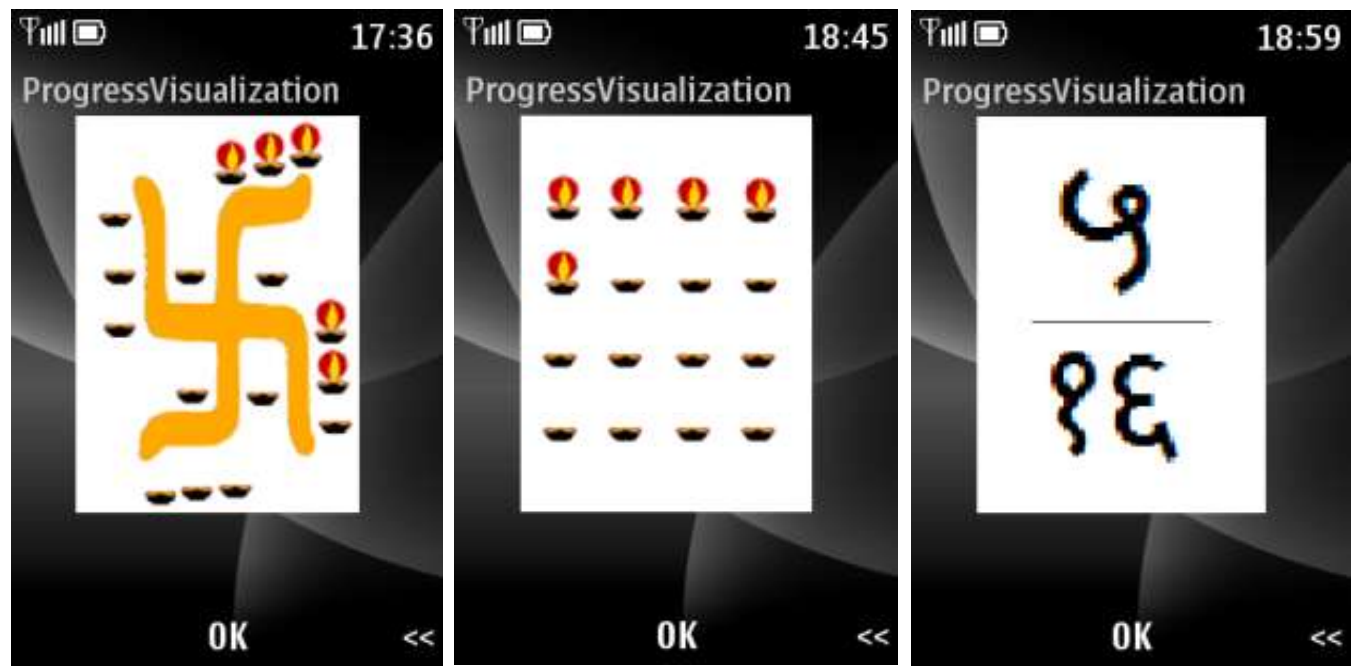

Figure 6.2: Report Card application with toned down cultural elements (center and right) preferred among mothers in Adoption Stage, versus cultural diya visualization (left) preferred by mothers in the passive stages.

However, after women have graduated to subsequent stages of development, NGOs observed they do not require such entertainment elements to engage their interest, since they had already started to witness the benefits of learning new topics, e.g. how to bake a new dish. For instance, women in later stages told us they wanted to see more recipes in Baking Trainer. As such, once women have advanced to the active stages of development, they exhibited a need for applications with more educational content. Similarly, while we used cultural elements such as diyas (lights) in Report Card to represent scores using more culturally familiar symbols (e.g.: 5 diyas to represent 5 modules finished), women in later stages said they preferred to have numeric symbols representing the scores instead. It turned out that while the women struggled with arithmetic, they had been attending adult literacy workshops and have been acquiring numeracy skills. Numbers in user-interface design allowed them to practice these skills.

\section{Transition from Trainer to On-the-job Assistant}

Moreover, instructional design needs to transition from the application as a "trainer" to the application as "on-the-job assistant." For example, while women in the Participation stage found the training materials in Baking Trainer application useful, women in the Adoption stage (who, unlike the former, are already cooking for living) requested modifications to make the application more useful in helping them in the kitchen with their tasks while they are performing baking tasks. For instance, latter women told us they cannot look at phone's screen when they are cooking, and want the application's design to emphasize more audio (vs. visual) instructions to remind them about recipe steps when they are baking. 


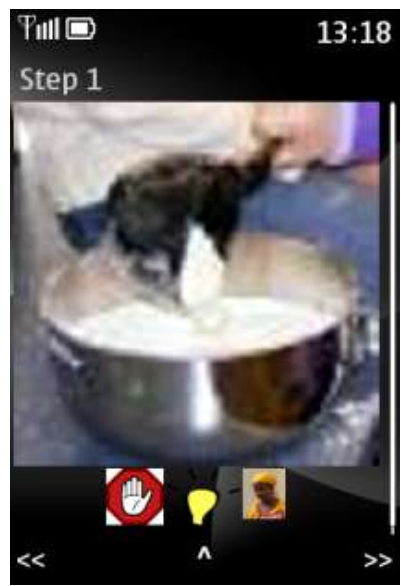

Figure 6.3: Baking Trainer with the addition of elements to hear precautions (stop sign) and tips (lightbulb).

In addition, while women in the Participation stage wanted phone book elements built into the Baking Trainer application to connect with the head chef and staff member (i.e., pictures of head chef or staff member that could be clicked to automatically call them through the application interface itself, bypassing the need to navigate the phone book) in order to seek additional assistance, women in the Adoption stage wanted similar pictorial phonebook features not to seek help, but to ask about additional tasks to be completed for the day (Figure 6.3).

\section{Fade Out Scaffolding Supports}

From co-design sessions using the Baking Trainer application, we found that the scaffolding supports in an application's instructional designs should also be structured such that it fades out as the user becomes more accomplished at her task. However, while instructional design principles often recommend that scaffolding support be gradually removed so that the learner does not become over-reliant on them, we did not witness this tendency among the women in our co-design sessions. Instead, we observed that women from the Adoption stage tried out the application on their own, and wanted the audio prompts to remind them about tips (e.g.: poke fork into potato for faster boiling) and precautions (e.g.: wait 15 minutes to allow for cooling before peeling the potato) only when they could not recall these steps, while women in the preceding Participation stage wanted the tips and precautions to be played out as part of all relevant cooking instructions. 




Figure 6.4: Interfaces for women to verify physical change received from a financial transaction with a shopkeeper or auto-rickshaw driver.

\section{Design for Increasing Levels of Economic Independence}

The applications must also support unique challenges faced by illiterate or semi-literate women acquiring higher levels of economic independence. For instance, NGOs claimed that during the Adoption stage, in the context of the Baking Trainer application, women undertake increasingly more financial transactions in their daily lives, e.g. buying food ingredients from the market, taking public transport to NGO premises, and receiving payments from NGOs or customers. With these evolving daily contexts, NGOs claimed that women need money counting trainers and assistants (such as interfaces shown in Figure 6.4) to address new challenges such as getting cheated due to lack of change counting abilities, or difficulty in totaling savings and preparing budgets at home and work.

\subsubsection{Design to Promote Relationship Building Within Communities}

NGO staff felt technologies can increase communication and improve trust between different social groups as the women progress through the stages of empowerment. We found that designs for earlier stages should support NGO to communicate with community members for instances such as planning events with local agents or to remind women of items learned in workshops (eg: wash hands before cooking). Designs in active stages should allow women in earlier stages of empowerment to clear their doubts or voice needs to women in more advanced stages of empowerment, enable women in similar stages to help one another in managing their daily tasks, and even assist women in advanced stages in recruiting community members to NGO initiatives. 


\section{NGOs and Local Agents}

NGOs wanted to combine the SMS Relationship Building and Survey applications to assist in their communications with local agents (eg: women/youth forums, local political/religious figures, etc). Since it is difficult to reach out to women directly in the Powerlessness stage, NGO staff want to be able to plan interventions with local agents by sending mass SMS messages to them about the time and day of a last-minute event and collect indicators from particular households in tracking women's progress, and so on, so that women's specific concerns or needs (such as self-defense strategies, employability skills, or baby care skills training) in those particular communities are taken into consideration, complementing their best practice of women's driven event topics.

\section{NGO Agents and Women/Families}

One of the best practices during the Initiation stage is for staff members to focus on their relationship building with the women and their families, so that the women will be allowed to actively join NGO initiatives. To ensure the comfort of families in attending events, staff members sometimes need to invite women and families from different demographics, such as by caste or religion, separately, and NGOs wanted the SMS Relationship Building application to provide a way to invite multiple members of particular demographics at a time. When staff members send reminders or to check up on the women's progress in practicing the items learned in the workshop at home, and whether they will be attending the next NGO event, NGOs felt women can build a relationship of trust with staff members outside of the events. Such interactions were not possible, or were only intermediated through the local agents, but through a family member owned cell phone, the staff members can directly interact with the women and their families over a distance.

\section{Woman and Husbands}

NGO staff members felt the SMS Relationship Building application could enable husband/wife interactions during the Powerless and Initiation stages, since the male members of the family own the cell phone, and women need to request access to the phone to see the message, or male members can proactively relay messages from their phone to the women. Even if such an application puts the husbands in a position of control in the initial stages of empowerment, the NGO agents claim that such types of social interactions between men and women in the households could be very useful in facilitating women and their families in passive stages to start transforming themselves into a more open and active mindset, while not threatening existing intra-family social hierarchies that men and women are comfortable with.

\section{Women and Intermediaries}

In addition to husbands, in the case of the SMS Relationship Building application, local agents or other literate family members may also serve as intermediaries in conveying messages to women. In earlier stages of empowerment when women are unfamiliar with technologies, NGOs felt that intermediated usage when children, other family members, neighbors, or local agents help women interact with the Awareness Building Stories application or other educational 
technologies are additional examples of the relationships that can be strengthened through the intermediated usage of ICTs.
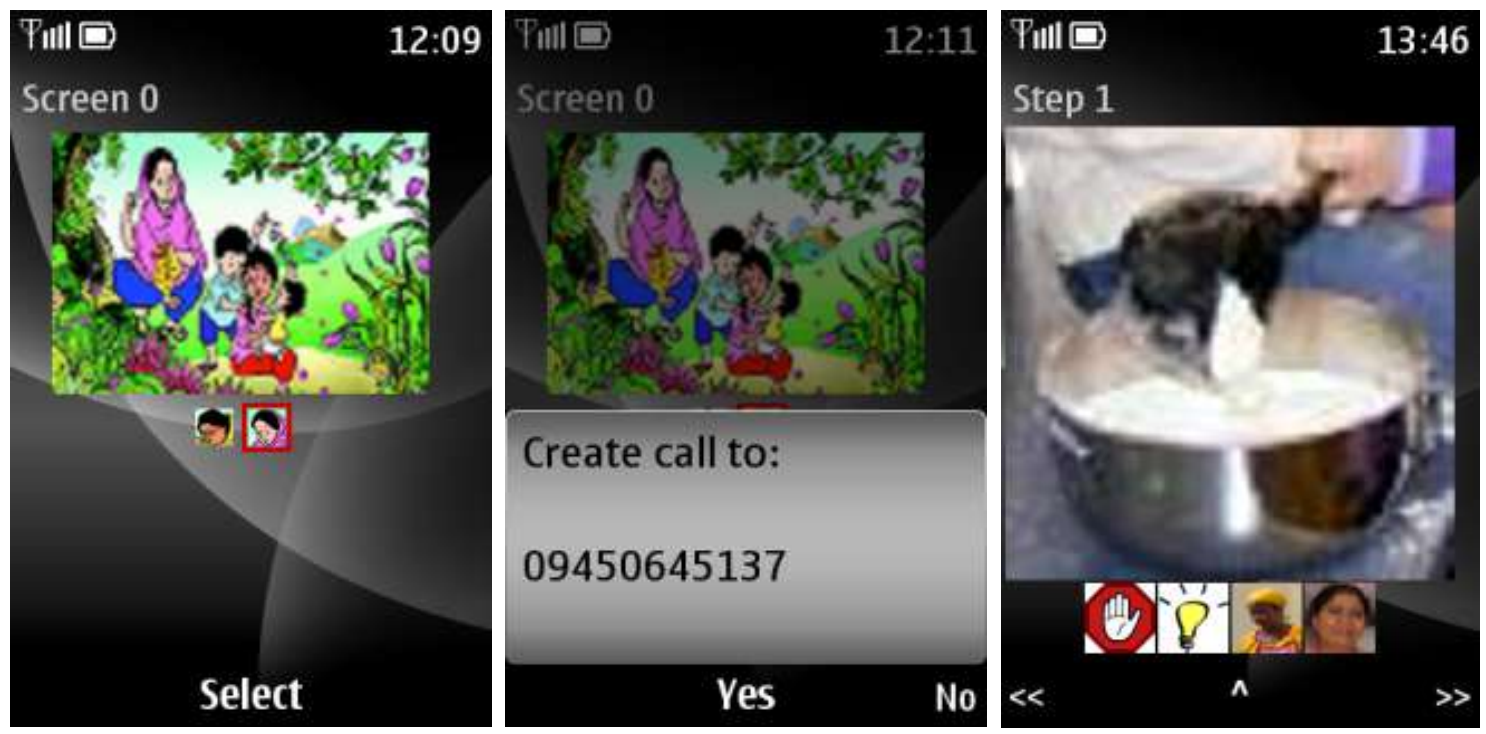

Figure 6.5: Awareness Building Stories application with pictures for user to click on to call a women in an advanced stage of empowerment or the local healthcare social worker (left and center). Baking Trainer application with similar elements for user to contact head chef (woman who has reached leadership stage) or NGO staff member (right).

\section{Women with women in advanced stages of empowerment}

We observed a common theme in the Awareness Building Stories and Baking Assistant applications that women graduating to higher stages of empowerment, in addition to training material, want people who can address their questions. On trying out the Awareness Building Stories application, the Initiation stage women voiced that they would like to be able to connect with other women in the community who had already completed the steps taught in the application, or with local government health-care social workers through pictorial phone book elements representing these women as shown in Figure 6.5. Similarly, during co-design using the Baking Trainer application, Participation stage women wanted to connect with the head chef (a woman who has reached the Leadership stage) or the NGO agent through similar pictorial phone book elements built into the application interface as shown in Figure 6.5. In addition to voice calls, the women also felt SMS could enable them to seek help from advanced women for help during training, if they had intermediaries who could assist them.

\section{Women with women in the same stage of empowerment}

Women in later stages wanted to seek help/support from each other, so they could all do a better job. In the Morning Reminders application, NGOs feel that collaborative progress of women and the strengthening of support groups can be established in the absence of the NGOs, which is one of their best practices. The women felt that they could strengthen their relationships and support 
for one another by helping to remind each other of different tasks. In this way, there is a collaborative sisterhood that is formed, where the women help each other in progressing through the stages of empowerment. Staff members claim that women tend to move faster through the empowerment trajectory when they are part of a collaborative and strong support group.

\section{Women and Family/Community}

In later stages of empowerment, NGOs claimed that women increase interactions with family members, and move onto interactions at the community level. NGO staff felt the Report Card application can enable mother-child interactions, when she encourages the children to complete all mobile learning classes. NGO staff also felt the application could enable mother-family and mother-mother interactions when she shares information about the child's progress with family members and other mothers, nurturing healthy developmental social interactions and involvement within the family and community.
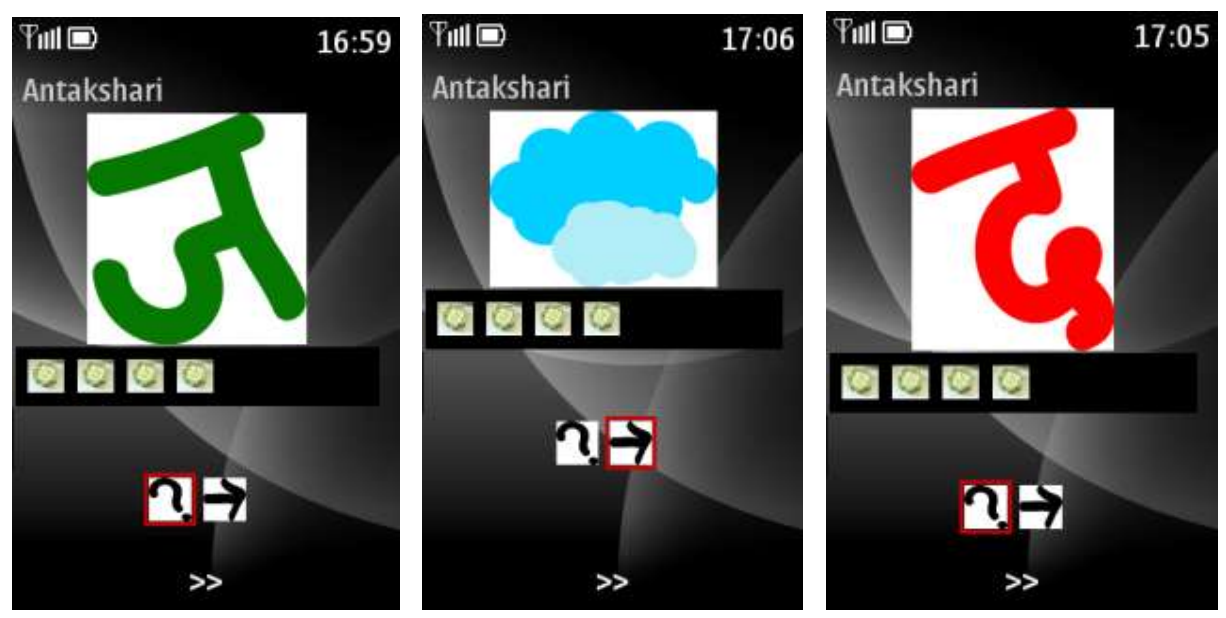

Figure 6.6: Community Recruitment application with intermittent screen (center) that asks a developmental question to ponder on, instead of posing a letter to start singing a song from (left, right).

Additionally, NGOs wanted the Community Recruitment application to train women in the Leadership stage to give back to the community. Some staff members wanted designs to complement the preparation phase for a community service idol (individual who has contributed the most to their community) program. They wanted women in the local physical forums to discuss and foster the attainment of their social, economic, and political aspirations - "what have you done as a citizen today", "what did you do for your community", "how far have you gotten on your dream", "who is the real hero of this village/town", and so on, through questions intermittently asked by the cell phone in between the Antakshari songs (as represented by the screen with clouds in Figure 6.6). What the staff members felt was even if the women did not explicitly answer the questions, it would provide a thought stimulus to the women on these community development topics, which in turn would motivate the women to take proactive steps to help their community members, as part of their preparations to become the next community service idol. 


\subsubsection{Design to Promote Holism Across Different Stages of Development}

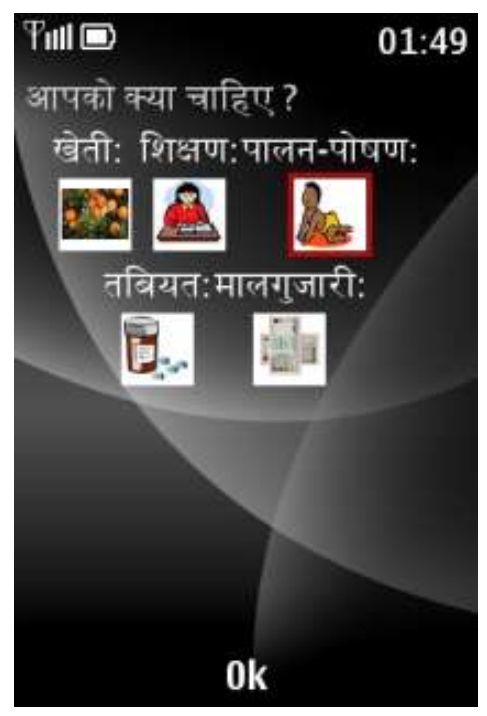

Figure 6.7: Screen promoting holism by presenting a menu of different developmental topics.

NGOs felt it was important to assist women in a holistic manner through designs that avoid supporting each stage of empowerment in the absence of considering how it connects to other stages, and to track women's progress in different developmental topics as she progresses through the stages of empowerment. Staff members mentioned that they would like for the mass SMS Relationship Building application to link back to the Household Surveys application, so that they can keep track of which topic and what progress has been made by the women. For better monitoring and interaction with the women, the staff members also suggested for mobile versions of the application for themselves. When co-designing with the NGO staff members, they re-iterated that one of their best practices is to hold sessions on multiple different topics of development for a holistic understanding of what development is and why it is useful to the women and their families. NGO staff wanted a pictorial menu representing different topics such as education of a girl, growing mango trees, and getting babies vaccinated, among others, for the women to navigate through, think about, and select (shown in Figure 6.7). NGO staff mentioned that this process would help the women see and explore all the topics from a high-level and would facilitate their best practice of having women reflect on previous topics in their free time, before the next NGO intervention on a new topic.

\subsection{Lesson \#3: Design for NGO Integration with State, National, and International Programs}

One of the NGO best practices is to integrate their grassroots initiatives with related programs at the state, national and international levels. In context of the Household Surveys application that could be used at any stage of empowerment, while certain more established organizations collect indicators such as those listed by the UN in the MDG targets or in other state and national surveys (number of children, number of girls in school, number of boys in school, income levels 
of the households, percent income contributed by female members, land ownership, etc), many newer organizations mentioned that they do not collect all the necessary information about their participants in order to be able to integrate or compare their participant results with state, national and other international level surveys. Staff members from more nascent organizations claimed that they do not have the man power to research resources such as national surveys, government publications, etc. in defining appropriate indicators for collection. By making state, national and international formal surveys available to the Household Surveys application in the form of mobile survey templates, the staff members claimed that this would enable them to collect all necessary indicators during their meetings with the participants, save on upfront survey creation time, skip data entry time, and would speed up their analysis and evaluation processes.

The NGO staff felt they could use such data and analyses so as to ensure that their interventions are meeting targets defined in state, national, and international programs such as target success rates of literacy drives, or to compare the results of their interventions with international development gender index measures in other states and countries. The NGO staff felt that such findings could then be used by them to present their successes to the respective higher up funding or government bodies at local, state, national and international levels for purposes such as follow-up fund-raising and to advocate policy-changes.

\subsection{Lesson \#4: Scope for Overlap in Designs for Working Moms in Industrialized Nations}

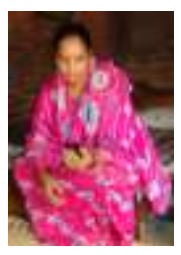

(a)

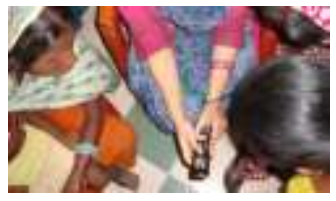

(d)

(b)
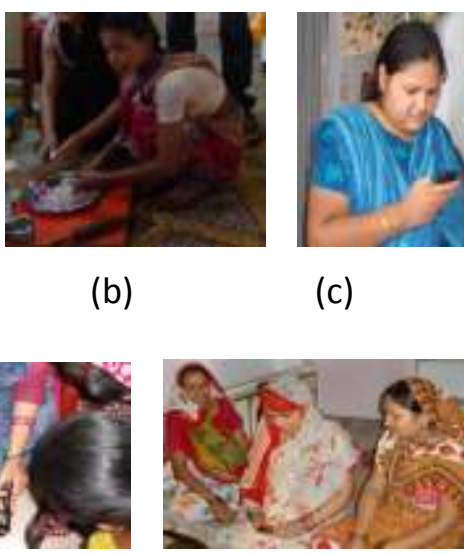

(e)

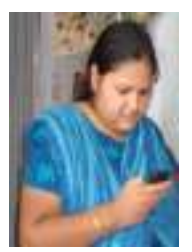

(c)

Figure 6.8: Sample situations where women in active stages (Participation, Adoption, Leadership) of empowerment can benefit from ICTs: (a) at home before getting started with the day, (b) at work with other colleagues, (c) on the way to work, (d) at an NGO workshop, (e) in free time at home with other female relatives and neighbors.

Demands on women in the last two stages appear to resemble those of working moms in industrialized nations. Some sample situations where women in active stages can benefit from ICTs are shown in Figure 6.8, some of which overlap with daily scenarios experienced by women in the industrialized world. During discussions using the Community Recruitment 
application, during the Leadership stage, women felt they had more time on their hands to help other women in the community, since their family and other community members are more supportive of their earlier efforts and help them more with household and sometimes even work tasks. This is because the family has experienced the socio-economic benefits of the women's initiatives. Sometimes, women from the earlier stages grow with the NGO and even become a staff member of the NGO, and reach out to other communities as part of their day job. With the increased time on their hands, they also have the time to mix their passion for social work with entertaining activities such as spending time with other women, similar to women in the industrialized world who pursue community service initiatives in their free time. During discussions with women using the Morning Reminders applications, the needs of women in the second last stage appear to resemble those of other career women in industrialized nations, where women in this stage complained about the difficulty in balancing home and work tasks, since their families were not always supportive. NGO staff and women felt that ICTs need to facilitate balancing work and home for the women, which is a common challenge for working men and women in the Western world.

\subsection{Lesson \#5: In considering technology platform, keep in mind user's readiness to be proactive}

Both the NGOs and women indicate that differences in individual ownership of technology suggest different design directions: from communal technology platforms in passive stages (television or radio) to more individual platforms (e.g. cell phone) in active stages. Male family members own cell phones but are not accustomed to sharing the cell phone for long periods with women in their households, since the cell phone is considered a resource mostly for the privileged (male) individuals in the family. On the other hand, when women approach economic independence in the Adoption and Leadership stages, they buy cell phones for themselves. Furthermore, in the Participation and Adoption stages, we noticed that women preferred using the cell phone over the television or radio for applications such as Baking Trainer, so that they could access the recipes at their own pace.

Coincidentally, there is another parallel here. In designing technologies for women in the developing world, perhaps the television and radio (which usually involves passive interaction from the viewer once switched on) are suitable media to communicate information to women in the passive stages of empowerment, while cell phones might be more suitable in later stages when women are more empowered to advance their own well-being. This observation is in line with NGO the best practice of having women take as much personal responsibility as possible in later stages. It also implies that the nature of the technology platform to target is not so much constrained by ownership patterns as the user's readiness to use it actively to access information beneficial for the user's personal development. 


\section{Section 7}

\section{Conclusion and Future Work}

While the best efforts of NGOs have enabled thousands of marginalized women throughout the developing world to contribute to their own well-being, and that of their families and communities in escaping the vicious cycle of poverty, there is a yet a long distance to achieving the United Nations Millennium Development Goals - for both greater gender equality and other developmental targets all broadly related to gender equality. We presented a five-stage model of women's development, conditions informed by NGO best practices that can aid women's graduation to later stages of empowerment, and fleshed out the design space using lessons from our co-design sessions with NGOs and women. We hope that the results here provide a starting point for informing the rest of the HCI community to perform further research on how technology can be designed, not only to promote women's empowerment around the world, but to also enable low-income women to escape the vicious cycle of poverty.

In our model, we have shown how women in different developmental stages could and should be thought of as users with very different characteristics and conditions that can facilitate their graduation from each stage of empowerment. NGOs ensure conditions such as the family being supportive of the woman's participation in developmental initiatives. NGOs also conduct awareness and training programs, and aim to build relationships of trust within the community to help women in their escape path from poverty and discrimination.

We have learned that technology designs can promote these conditions for assisting women to break free from the vicious cycle of poverty. We have shown how designs can enable family members to be involved in NGO initiatives by having husbands as technology intermediaries for women, and by enabling women to share information about developmental activities with other family members. In complementing educational programs, we have shown how designs need to promote an instructional sequence that leverages cultural elements to overcome fear of technology, use entertainment to interest women in the developmental topics, subsequently incorporate symbols to reinforce emerging literacy practices, and eventually remove scaffolds to support a sense of independence. In addition, there needs to be designs that integrate local to global level initiatives for a greater developmental impact. Most importantly, learning does not take place in isolation. Technology designs need to foster expanding learning communities where women in earlier stages can improve trust with NGOs and local agents, and women in advanced stages can give back by supporting the growth of women in earlier developmental stages and to recruit additional members of the community to NGO initiatives.

With these new perspectives that we have introduced to the design space for assisting lowincome women to escape the vicious cycle of poverty, future research will need to investigate if technology can be used to increase the proportion of women graduating to each next stage of empowerment, as well as to accelerate the empowerment process for women in the developing world, such as in shortening the time they need to graduate from a developmental stage to the next. Applications such as the Household surveys can be explored for data collection at all stages 
and automated data analysis while on the field, in order to help NGOs plan interventions that can increase the proportion of graduating women as well as to help NGOs make faster decisions about interventions in order to accelerate women's progression through the various stages. In addition, the use of religious design artefacts might interest the women in developmental topics and enable family support that is important for long term engagement in NGO activities.

Since the proportion of women and the speed of graduation is slowest during the passive stages of empowerment, and since our user population was skewed towards more active stages of empowerment, future work can open up the design space by further exploring the design needs of passive stage women, at the Powerlessness and Initiation stages in particular. Since women are traditionally denied access to resources such as cell phones in passive stages, our NGOs respondents are particularly excited about exploring if they could loan or donate cell phones to women in these stages. NGOs feel the Initiation stage is most promising, since women have already overcome family barriers in attending their first few NGO events, and there is a lower risk of donated cell phones being snatched away from the women by other members of the family or community. In addition, NGOs are also interested in exploring the use of communal technologies, such as the television and radio platforms, in addressing the needs of women in the Powerlessness stage. We believe that such collaborations will allow the HCI community to push the boundaries of the design space that has been outlined in this thesis. 


\section{Bibliography}

[1] Millennium Development Goals. http://www.un.org/millenniumgoals/gender.shtml

[2] Millennium Development Goals 2010 Progress Report. http://www.un.org/millenniumgoals/pdf/MDG\%20Report\%202010\%20En\%20r15\%20low\%20res\%2020100615\%20-.pdf

[3] United Nations Foundation, Why Invest in Adolescent Girls, p. 1. Available at http://www.clintonglobalinitiative.org/ourmeetings/PDF/actionareas/Why_Invest_in_Ado lescent_Girls.pdf.

[4] UN Secretary-General Report, In-depth Study on all Forms of Violence against Women, Advance of Women, 2006.

[5] Kristof, N. D, WuDunn, S. Half the Sky: Turning Oppression into Opportunity for Women Worldwide, September 2009.

[6] Engendering Development Through Gender Equality in Rights, Resources, and Voice. World Bank Policy Research Report, Washington, D.C.: World Bank, 2001.

[7] The State of the World's Children 2007: Women and Children, the Double Dividend of Gender Equality, UNICEF (New York), 2006.

[8] United Nations Development Programme: Global Partnership for Development, United Nations Development Programme Annual Report 2006, UNDP (New York), 2006.

[9] Ricardo Hausmann, Laura D. Tyson, Saadia Zahidi, Editors (2009). The Global Gender Gap Report 2009, World Economic Forum, Geneva, Switzerland.

[10] Nike Foundation, The Girl Effect: Not Just about Girls: Engaging Men and Boys Is Key to Girls' Ability to Achieve their Full Potential, 2009. Available at www.nikefoundation.com/media_room.html

[11] Burger, C. J., Creamer, E. G., Meszaros, P.S. Reconfiguring the Firewall: Recruiting Women to Information Technology across Cultures and Continents. AK Peters, Ltd., Wellesley, MA, 2007

[12] Kafai, Y. B., Heeter, C., Denner, J., and Sun, J. Y. Beyond Barbieß and Mortal Kombat, New Perspectives on Gender and Gaming, MIT Press, Cambridge, MA, 2008

[13] Cassell, J. "Genderizing HCI." In J. Jacko and A. Sears (eds.), The Handbook of HumanComputer Interaction. Mahwah, NJ: Lawrence Erlbaum, pp. 402-411, 2002

[14] Ramachandran, D., Canny, J., Das, P. D., and Cutrell, E. 2010. Mobile-izing health workers in rural India. In Proceedings of the 28th international Conference on Human Factors in Computing Systems (Atlanta, Georgia, USA, April 10 - 15, 2010). CHI '10.

[15] Ramachandran, D., Goswami, D.,Canny, J. Research and Reality: Using Mobile Messages to Promote Maternal Health in Rural India. In Proceedings of the International Conference on Information and Communication Technologies and Development (London, England), December 13-16, 2010 
[16] Jensen, R., Oster, E., The Power of TV: Cable Television and Women's Status in India, The Quarterly Journal of Economics, MIT Press, vol. 124(3), pages 1057-1094, August 2007.

[17] Alam, Q., Yusuf, M. A., Coghill, K. Village Phone Program, Commodification Of Mobile Phone Set And Empowerment Of Women, Gender in Community Informatics; Journal of Community Informatics, vol. 5 no. 3, 2010

[18] Parikh, T. S., Javid, P., K., S., Ghosh, K., and Toyama, K. Mobile phones and paper documents: evaluating a new approach for capturing microfinance data in rural India. In Proceedings of the SIGCHI Conference on Human Factors in Computing Systems (Montréal, Québec, Canada, April 22 - 27, 2006).

[19] Sharma, C., Sharma, S., Subhedar, U. Putting ICTs In the Hands of the Women of Kanpur and the Chickan Embroidery Workers of Lucknow, Journal on Information Technologies and International Development, Special Issue: Women's Empowerment and the Information Society, Vol. 4, Issue 2, pp. 11-16, Winter 2007.

[20] Davis, S. S. Empowering Women Weavers? The Internet in Rural Morocco, Journal on Information Technologies and International Development, Special Issue: Women's Empowerment and the Information Society, vol. 4, issue 2, pp. 17-23, Winter 2007.

[21] Medhi, I., Menon, G., and Toyama, K. 2008. Challenges in computerized job search for the developing world. In CHI '08. ACM, New York, NY, 2079-2094.

[22] Wendy M Walker, Shalini P Vajjhala Gender and GIS: Mapping the Links between Spatial Exclusion, Transport Access, and the Millennium Development Goals in Lesotho, Ethiopia, and Ghana Gender in Community Informatics; Journal of Community Informatics, vol. 5 no. 3, 2010

[23] Wheeler, D. L. Wheeler, Empowerment Zones? Women, Internet Cafés, and Life Transformations in Egypt, Journal of Information Technologies and International Development, vol. 4, Issue 2, pp. 89-104, Winter 2007

[24] Bardzell, S. Feminist HCI: taking stock and outlining an agenda for design. In Proceedings of the 28th international Conference on Human Factors in Computing Systems CHI '10. ACM, New York, NY, 1301-1310.

[25] Sambasivan, N., Cutrell, E., Toyama, K., and Nardi, B. 2010. Intermediated technology use in developing communities. In CHI 2010.

[26] Longwe, S. H. Gender Awareness: The Missing Element in the Third World Development Project. In Wallace, Tina and Candida March (eds.) (1991). Changing Perceptions: Writings on Gender and Development. Oxford, England: Oxfam.

[27] OECD Evaluation. http://www.oecd.org/dataoecd/46/47/43041409.pdf

[28] Hafkin, J. N., Huyer, S. Women and Gender in ICT Statistics and Indicators for Development, Journal on Information Technologies and International Development, Special Issue: Women's Empowerment and the Information Society, Vol. 4, Issue 2, pp. 25-41, Winter 2007.

[29] Blumenstock, J., Eagle, N. Mobile Divides: Gender, Socioeconomic Status, and Mobile Phone Use in Rwanda, in Proc. ICTD 2010. 
[30] Ramachandran, D., Kam, M., Chiu, J., Canny, J., and Frankel, J. F. 2007. Social dynamics of early stage co-design in developing regions. In Proceedings of the SIGCHI Conference on Human Factors in Computing Systems CHI '07.

[31] First official estimate: An NGO for every 400 people in India. http://www.expressindia.com/latest-news/First-official-estimate-An-NGO-for-every-400people-in-India/643302/

[32] Meena comic series. http://www.unicef.org/rosa/Rosa_meena_baby_ranis_four_visits.pdf

[33] Kumar, A., Tewari, A., Shroff, G., Chittamuru, D., Kam, M., and Canny, J. 2010. An exploratory study of unsupervised mobile learning in rural India. In Proceedings of the 28th international Conference on Human Factors in Computing Systems CHI '10. ACM, New York, NY, 743-752 